\title{
Anesthesiology
}

\section{Rufinamide Attenuates Mechanical Allodynia in a Model of Neuropathic Pain in the Mouse and Stabilizes Voltage-gated Sodium Channel Inactivated State \\ --Manuscript Draft--}

\begin{tabular}{|c|c|}
\hline Manuscript Number: & ALN201202011R2 \\
\hline Full Title: & $\begin{array}{l}\text { Rufinamide Attenuates Mechanical Allodynia in a Model of Neuropathic Pain in the } \\
\text { Mouse and Stabilizes Voltage-gated Sodium Channel Inactivated State }\end{array}$ \\
\hline Article Type: & Pain Medicine \\
\hline Corresponding Author: & $\begin{array}{l}\text { Marc R. Suter, M.D. } \\
\text { University Hospital Center and University of Lausanne } \\
\text { Lausanne, SWITZERLAND }\end{array}$ \\
\hline \multicolumn{2}{|l|}{$\begin{array}{l}\text { Corresponding Author Secondary } \\
\text { Information: }\end{array}$} \\
\hline Corresponding Author's Institution: & University Hospital Center and University of Lausanne \\
\hline \multicolumn{2}{|l|}{$\begin{array}{l}\text { Corresponding Author's Secondary } \\
\text { Institution: }\end{array}$} \\
\hline First Author: & Marc R. Suter, M.D. \\
\hline \multicolumn{2}{|l|}{ First Author Secondary Information: } \\
\hline \multirow[t]{5}{*}{ Order of Authors: } & Marc R. Suter, M.D. \\
\hline & Guylène Kirschmann \\
\hline & Cedric Laedermann, M.Sc. \\
\hline & Hugues Abriel, M.D., Ph.D. \\
\hline & Isabelle Decosterd, M.D. \\
\hline \multicolumn{2}{|c|}{ Order of Authors Secondary Information: } \\
\hline Abstract: & $\begin{array}{l}\text { Background: Voltage-gated sodium channels dysregulation is an important feature of } \\
\text { hyperexcitability leading to pain persistence. Sodium channel blockers currently used } \\
\text { for the treatment of neuropathic pain are poorly tolerated or not available orally. Getting } \\
\text { new molecules to clinical use is an arduous process and we here propose to use a } \\
\text { sodium channel blocker already marketed as anticonvulsant, rufinamide. } \\
\text { Methods: We tested rufinamide on the Spared Nerve Injury model of neuropathic pain } \\
\text { in mice. We compared its effect on mechanical allodynia to amitriptyline. The effect of } \\
\text { rufinamide on sodium currents was tested using patch clamp in human embryonic } \\
\text { kidney } 293 \text { cells expressing the voltage-gated sodium channel Nav1.7 isoform and on } \\
\text { freshly dissociated dorsal root ganglion neurons and compared to amitriptyline and } \\
\text { mexiletine. } \\
\text { Results: In naive mice, amitriptyline (20mg/kg) increased withdrawal threshold to } \\
\text { mechanical stimulation from } 1.3 \mathrm{~g}(0.6-1.9) \text { (median ( } 95 \% \text { confidence interval)) to } 2.3 \mathrm{~g} \\
(2.2-2.5) \text { and latency of withdrawal to heat stimulation from } 13.1 \mathrm{~s}(10.4-15.5) \text { to } 30.0 \mathrm{~s} \\
(21.8-31.9), \text { whereas rufinamide had no effect. Rufinamide and amitriptyline alleviated } \\
\text { injury-induced mechanical allodynia-like behavior for } 4 \text { hours (maximal effect from } \\
0.10 \pm 0.03 \mathrm{~g} \text { (mean } \pm S D) \text { to } 1.99 \pm 0.26 \mathrm{~g} \text { for rufinamide and from } 0.25 \pm 0.22 \mathrm{~g} \text { to } 1.9 \pm 0.8 \mathrm{~g} \\
\text { for amitriptyline). } 24 \text { hours later, the effect had worn off. All drugs reduced peak current } \\
\text { and stabilized the inactivated state of voltage-gated sodium channel Nav1.7 in cell } \\
\text { expression system, with similar effects in dorsal root ganglion neurons. } \\
\text { Conclusions: At doses alleviating neuropathic pain, amitriptyline showed alteration of } \\
\text { behavioral response possibly related to either alteration of basal pain sensitivity or/and } \\
\text { sedative effect. Side effects and drug tolerance/compliance are major problems with } \\
\text { drugs such as amitriptyline. Rufinamide seems to have a better tolerability profile. Our } \\
\text { results suggest rufinamide could be a new alternative to explore for the treatment of } \\
\text { neuropathic pain. }\end{array}$ \\
\hline
\end{tabular}


Dear Professor Brennan,

We are pleased to resubmit a fully revised version of our manuscript "Rufinamide attenuates mechanical allodynia in a model of neuropathic pain in the mouse and stabilizes voltage-gated sodium channel inactivated state" for consideration for publication. Following your decision letter of June $7^{\text {th }} 2012$, we revised the manuscript according to the constructive points raised by your statistical reviewer and addressed the missing parts.

Responses to the Reviewer \#4:

Global response: We changed the description of the statistical method (p. 3, I. 19), according to the changes mentioned in the point-to-point response below.

\section{Abstract}

1. This is simply an opinion and the authors are encouraged to revise their abstract as they see fit. Although describing the results of the study using a narrative style can often convey the findings of the study, it is far more informative to report the actually observed effects using descriptive statistics and measures of effect size (e.g., mean differences, odds ratios, etc.).

Response: We thank the reviewer for the remark. We changed the abstract and added median with 95\% confidence interval for withdrawal threshold and withdrawal latency in naïve animals as well as the mean values $\pm S D$ of withdrawal threshold after SNI at the peak effect for the highest drug dose. We also added these values in the result section under point 1.1 to 1.3.

We did not add the values for the global effect on the stabilization effect of inactivation properties of Na channels (values of V1/2 inactivation, recovery from inactivation, and activity dependent block for each drug) because of word limitation of the abstract.

Introduction

2. When conducting inferences (i.e., significance testing using $\mathrm{p}$ values) it is important to formally state a hypothesis to test. If a $\mathrm{p}$ value is reported, a hypothesis is being tested. Explicitly state the hypothesis(es) in the Introduction section will provide a wealth of information to your readers concerning the expected results of the study.

Response: We added the null hypothesizes tested in our experiments at the end of the introduction ( $p$. 6, I. 28)

\section{Methods}

3. It is important to define the measures of central tendency AND variability when they are reported in the methods section (e.g., mean +- SD). At present a value is reported in the methods before they are introduced in the stats section. Is this value a mean +- SD?

Response: We agree with the reviewer. The only value mentioned with variability in the method section is the room temperature and we changed it to $21^{\circ} \mathrm{C}(\mathrm{p} .7,1.44)$. This is how it is set in the animal facility but we do not have the control measurement to give a precise range of temperature at that period of time. We apologize for mentioning variability in the previous version. 
4. Please ensure that exact sample sizes are available for all comparisons. Of note is that reporting a sample size range (e.g., " $\mathrm{n}=4-10 "$ ) is insufficient in this regard.

Response: We apologize for this ambiguity which was corrected in the method section (p. 9, I. 37).

\section{Statistical Methods}

5. Several of the variables under study may violate the assumptions of parametric tests (e.g., normality, homogeneity of variances, level of measurement), were such assumptions considered prior to conducting the analysis? Several of the descriptive statistics appear to be quite skewed, leading to the fear that these data do not satisfy parametric assumptions. Please reconsider the approach.

\section{Response:}

We apologize if our assumptions of normality and homogeneity of variance of our variable was erroneous for some variables. As it is not clear which variables are questioned by reviewer 4 , we go over all figures to hopefully clarify the analysis.

a) We considered the measurements of mechanical allodynia using logarithmic values for homogeneity of variance. Threshold responses are usually normally distributed. Sometimes the sample for one timepoint does not pass a normality test, but this was the exception and we assumed the whole population does. Mainly this occurs for baseline (BL) data which are skewed because the upper threshold is fixed at $2.56 \mathrm{~g}$ (with von Frey of higher values the paw of the mice is lifted passively) and the distribution is only one-sided. We therefore changed our analysis for the development of allodynia by using a non-parametric test (Wilcoxon matched-pairs signed rank test); this concerns only the comparison of $B L$ versus preinjection (post nerve injury) values. The result reject the null hypothesis that the values are the same ( $p<0.05$ with Bonferrroni's correction for multiple testing). The two-way repeated measures ANOVA was then used from preinjection to $24 \mathrm{~h}$ post injection (precision below).

b) For measures of figure 2, some variables show a skewed distribution because of fixed thresholds. We changed the analysis to non-parametric Kruskal-Wallis test with Dunn's correction for multiple testings:

For the withdrawal threshold, we obtain the following

\begin{tabular}{|l|r|r|r|}
\hline Kruskal-Wallis test & & & \\
\hline P value & 0.0456 & & \\
\hline Number of groups & 6 & & \\
\hline Kruskal-Wallis statistic & 11.31 & & \\
\hline Dunn's Multiple Comparison Test & Difference in rank sum & Significant? P<0.05? & Summary \\
\hline RUF50vF vs DMSOvF & -4.438 & No & ns \\
\hline AMI10vF vs NaClvF10 & 13.69 & No & ns \\
\hline AMI20vF vs NaClvF20 & 16.88 & Yes & $*$ \\
\hline
\end{tabular}

For the withdrawal latency, we obtain the following

\begin{tabular}{|l|r|r|l|}
\hline Kruskal-Wallis test & $<0.0001$ & & \\
\hline P value & 6 & & \\
\hline Number of groups & 28.31 & & \\
\hline Kruskal-Wallis statistic & & \\
\hline
\end{tabular}




\begin{tabular}{|l|r|r|r|}
\hline Dunn's Multiple Comparison Test & Difference in rank sum & Significant? $\mathrm{P}<0.05$ ? & Summary \\
\hline RUF50HP vs DMSO-HP & 0.0 & No & ns \\
\hline AMI10HP vs NaCl-HP10 & 22.25 & Yes & $* *$ \\
\hline AMI2OHP vs NaCl-HP20 & 19.63 & Yes & $*$ \\
\hline
\end{tabular}

For the total activity, we obtain the following

\begin{tabular}{|l|r|r|r|}
\hline Kruskal-Wallis test & & & \\
\hline P value & 0.0192 & & \\
\hline Exact or approximate P value? & Gaussian Approximation & & \\
\hline Kruskal-Wallis statistic & 7.906 & & \\
\hline Dunn's Multiple Comparison Test & Difference in rank sum & Significant? P < 0.05? & Summary \\
\hline NaCl vs RUF50 & 0.3333 & No & ns \\
\hline NaCl vs AMI10 & 7.667 & Yes & $*$ \\
\hline RUF50 vs AMI10 & 7.333 & No & ns \\
\hline
\end{tabular}

We also changed figure 2 accordingly and present the data with Box-Plot (median, box for $25^{\text {th }}$ and $75^{\text {th }}$ percentile, whiskers representing the minimum and maximum data).

c) Electrophysiological measures in vitro:

Most datasets pass the Kolmogorov-Smirnov test for normality. Some $n$ are too small to perform normality tests. We assume thus that the general population of data in this section can be analyzed with parametrical tests.

As asked by the reviewer we changed the results and figures to show the exact $p$ values when adequate:

- for SSI: 0.0038 for RUF, 0.0019 for AMI and 0.0003 for MEX

-for RFI: <0.0001 for RUF (real value is 3.58E-10), 0.0011 for AMI and 0.0002 for MEX -for use-dependent block the tables were changed in figure 6

d) Electrophysiological measures ex-vivo:

Peak currents, activation, SSI and recovery from inactivation data are normally distributed and paired $t$-tests were used for comparison. Exact $p$-values are 0.0084 for peak current, 0.17 for $\mathrm{V} 1 / 2$ of activation, 0.35 for slope of activation, $<0.0001$ (0.00009) for V1/2 of steady-state inactivation, 0.34 for slope of steady-state inactivation and 0.028 for recovery from inactivation. These values, if not present were added in the text.

6. Please report the software that was used to conduct the statistical analyses in the statistical analysis section.

Response: We apologize for the omission which was corrected (p. 14, I. 2) "Statistical analysis was performed using Prism 5 for windows, version 5.03, GraphPad Software, San Diego California USA"

7. Please report the nature of the hypothesis testing (i.e., one-tailed versus two-tailed testing). Response: We apologize for the omission. This was corrected (p. 14, I. 0) "All hypotheses were challenged using two-tailed testing."

8. I had great difficulty following the analytical plan. As currently written, I could not replicate the analyses if given access to your data (which is the goal for this description). The elegant experimental 
design naturally leads to two-way repeated measures ANOVA and this approach is introduced. However, there are confusing statements in the statistical methods section that indicate that a nonconventional approach was taken to the analysis. Statements such as "?but the statistical analysis was done for each group separately" indicate that a series of one-way repeated measures ANOVAs were conducted (and the results certainly read this way as well). This approach does not formally test group differences over time/dose and would not apply the proper control for multiple comparisons. The authors are encouraged to seek statistical consultation (if necessary) to revise either the description of the plan, the actual plan, and the reporting of the results (a group $\mathrm{x}$ time interaction would be extremely helpful here).

Response: We apologize for the misunderstanding in the analytical plan by using the word "separately". As the different rufinamide doses were not performed at the same time (to many groups) and in order to provide a similar environment to treated and control mice, we used a control group each time. We used a two-way repeated measures ANOVA for each experiment. That is: - RUF $25 \mathrm{mg} / \mathrm{kg}$, RUF $50 \mathrm{mg} / \mathrm{kg}$ and DMSO30\%, $n=10,10$ and 9 respectively. Treatment comes as a significant source of variation with a $p=0.0009$, as well as time with a $p<0.0001$, Treatment $x$ time interaction is also source of variation with a $p$ at 0.0053 . Bonferroni's posttests comparing each timepoint after injection to the pre-injection value are shown on figure $1\left(^{*} p<0.05,{ }^{*} p<0.01\right.$, ${ }^{* * *} p<0.001$, the exact $p$ values are not given for post-hoc testing).

- RUF $5 \mathrm{mg} / \mathrm{kg}$, RUF $10 \mathrm{mg} / \mathrm{kg}$ and DMSO30\%, $n=8$ per group. Only time comes as a significant source of variation ( $p<0.0003$ ). $p=0.66$ for treatment and 0.46 for treatment $x$ time interaction. All pvalues for Bonferroni's posttests comparing each timepoint after injection to the pre-injection value are above 0.05 .

- AMI $10 \mathrm{mg} / \mathrm{kg}, A M I 20 \mathrm{mg} / \mathrm{kg}$ and saline, $n=10,10$ and 9 respectively. Treatment, time and treatment $x$ time interaction all contribute to variation with a $p<0.0001$. Bonferroni's posttests comparing each timepoint after injection to the pre-injection value are shown on figure $1\left({ }^{*} p<0.05,{ }^{* *} p<0.01\right.$, ${ }^{* * *} p<0.001$, the exact $p$ values are not given for post-hoc testing).

In fig 1, we averaged the two DMSO control groups for the clarity of the figure.

9. Related to the above, the practice of applying a series of unprotected paired t-tests in Figure 2 violates the Journal's family-wise error rate policy. Please revise this approach to account for the fact that multiple comparisons are being made.

Response: We thank the reviewer for this precision. The approach has been revised (see above, point 5).

\section{Results}

10. Although the reporting of $p$ values using " $p<"$ or " $p>$ " is still acceptable to many journals, reporting the exact $p$ values (e.g., $p=0.031$ ) is preferred. This reporting practice even applies to $p$ values that are statistically non-significant (e.g., $p=0.54$ )

Response: We changed wherever necessary with exact $p$ values, except for posttests when only the approximation is available in GraphPad $\left({ }^{*} p<0.05,{ }^{* *} p<0.01,{ }^{* * *} p<0.001\right)$. We also left " $p<$ " when more than 4 digits were necessary. 
11. Unless explicitly stated, it can often be difficult to tell if any of the measurements were lost to observation or were missing in the analysis. Were any data missing for any of the variables? The methods state that certain cells were not used in the analysis. Some estimates of the lost data must be provided to your reader.

Response: No data were missing for behavior after drug delivery. For electrophysiology, once the cells were sealed, around $15 \%$ of cells were lost before any measurement with drug could be completed. This was added in the method (p. 10, I. 48)

General

12. The reporting of standard error of the mean (SEM or SE) as a measure of variability is certainly commonplace and is routinely encountered. However, as a measure of variability, perhaps there are better choices than SEM. When simply describing the sample, standard deviation (SD) provides a measure of variability that is less abstract and can be directly used for standard effect size calculations. When appealing to the sampling distribution, +-SEM is actually a $68 \%$ confidence interval that is of little use for conventional inference testing. A much more informative choice would be to report a $95 \%$ confidence interval in the text, tables, and figures.

Response: We changed figure 1 to show SD instead of SEM as suggested by the reviewer. On figure 2 as mentioned above we changed the graphical representation to box-plot. SD was already used for the other figures.

13. The use of the term "significant" has been found without an important modifier in numerous places in the manuscript. While discussing a "significant effect" is relatively common, it is not nearly as informative (or precise) as discussing a "statistically significant effect" or a "clinically significant effect". Please reconsider the use of 'significant" throughout the manuscript.

Response: We thank the reviewer for the comment and verified the use of "significant" throughout the manuscript. 


\section{Rufinamide attenuates mechanical allodynia in a model of neuropathic pain in} the mouse and stabilizes voltage-gated sodium channel inactivated state

Marc R. Suter ${ }^{1,2}$, MD, Anesthesiology Fellow, Guylène Kirschmann ${ }^{1}$, Laboratory technician, Cedric Laedermann ${ }^{1,3}, \mathrm{MSc}$, PhD student, Hugues Abriel ${ }^{3}, \mathrm{MD}, \mathrm{PhD}$, Professor, Isabelle Decosterd ${ }^{1,2,4}, \mathrm{MD}$, Associate Professor

${ }^{1}$ Pain Center, Department of Anesthesiology, University Hospital Center and University of Lausanne, 1011 Lausanne, Switzerland (work attributed to)

${ }^{2}$ for the Swiss Pain Research Consortium, Zurich, Switzerland,

${ }^{3}$ Department of Clinical Research, University of Bern, Bern, Switzerland

${ }^{4}$ Department of Cell Biology and Morphology, University of Lausanne, 1011 Lausanne,

Switzerland

Corresponding author:

Marc R. Suter

Pain Center, Department of Anesthesiology

CHUV

Avenue du Bugnon 46

1011 Lausanne

Switzerland

Phone: +41 79 5563479, fax : +4121314 2004

Email: marc.suter@chuv.ch

This study was supported by the Swiss National Science Foundation (Swiss Pain Research Consortium, Special Program University Medicine grant, 33CM30-124117 to I.D. and M.S. and grant 310030B_135693 to H.A.), Bern, Switzerland, the Swiss Society of Anesthesiology, Bern, Switzerland and the University of Bern, Bern, Switzerland.

Work presented at:

International Association for the Study of Pain meeting, Montreal, Quebec, Canada, September 2010

Effect of rufinamide on gating properties of voltage-gated sodium channel Nav1.7, MR Suter, H Abriel, I Decosterd

European Society of Anaesthesiology meeting, Amsterdam, Netherland, June 2011

Rufinamide alleviates mechanical allodynia in a mouse neuropathic pain model 
MR Suter, G Kirschmann, H Abriel, I Decosterd

Number of words in Abstract (285), in Introduction (543), and in Discussion (1661)

Running title:

Rufinamide reduces neuropathic pain in the mouse

\section{Brief summary:}

The anti-epileptic drug rufinamide alleviates mechanical allodynia in a neuropathic pain model with less side-effect than amitriptyline, one of the first line treatments for neuropathic pain. Rufinamide stabilizes sodium channels in their inactivated state. 


\section{Abstract:}

Background: Voltage-gated sodium channels dysregulation is an important feature of hyperexcitability leading to pain persistence. Sodium channel blockers currently used for the treatment of neuropathic pain are poorly tolerated or not available orally. Getting new molecules to clinical use is an arduous process and we here propose to use a sodium channel blocker already marketed as anticonvulsant, rufinamide.

Methods: We tested rufinamide on the Spared Nerve Injury model of neuropathic pain in mice. We compared its effect on mechanical allodynia to amitriptyline. The effect of rufinamide on sodium currents was tested using patch clamp in human embryonic kidney 293 cells expressing the voltage-gated sodium channel Nav1.7 isoform and on freshly dissociated dorsal root ganglion neurons and compared to amitriptyline and mexiletine. Results: In naive mice, amitriptyline $(20 \mathrm{mg} / \mathrm{kg})$ increased withdrawal threshold to mechanical stimulation from $1.3 \mathrm{~g}(0.6-1.9)$ (median (95\% confidence interval)) to $2.3 \mathrm{~g}$ $(2.2-2.5)$ and latency of withdrawal to heat stimulation from $13.1 \mathrm{~s}(10.4-15.5)$ to $30.0 \mathrm{~s}$ (21.8-31.9), whereas rufinamide had no effect. Rufinamide and amitriptyline alleviated injury-induced mechanical allodynia-like behavior for 4 hours (maximal effect from $0.10 \pm 0.03 \mathrm{~g}(\mathrm{mean} \pm \mathrm{SD})$ to $1.99 \pm 0.26 \mathrm{~g}$ for rufinamide and from $0.25 \pm 0.22 \mathrm{~g}$ to $1.9 \pm 0.8 \mathrm{~g}$ for amitriptyline). 24 hours later, the effect had worn off. All drugs reduced peak current and stabilized the inactivated state of voltage-gated sodium channel Nav1.7 in cell expression system, with similar effects in dorsal root ganglion neurons.

Conclusions: At doses alleviating neuropathic pain, amitriptyline showed alteration of behavioral response possibly related to either alteration of basal pain sensitivity or/and sedative effect. Side effects and drug tolerance/compliance are major problems with drugs such as amitriptyline. Rufinamide seems to have a better tolerability profile. Our 
results suggest rufinamide could be a new alternative to explore for the treatment of neuropathic pain. 


\section{Introduction:}

Pain is essential for survival as it serves as an alert to engage protective behavior. Neuropathic pain defined by the International Association for the Study of Pain as "pain caused by a lesion or disease of the somatosensory nervous system" affects $7 \%$ of the population ${ }^{1}$ and possesses no protective purpose.

Sodium channels are major targets for the development of new drug to treat neuropathic pain $^{2}$. Nerve injury changes the expression (number, subtypes) of sodium channels ${ }^{3}$ which affects peripheral nerve hyperexcitability and ectopic discharges along the nerve, in the dorsal root ganglion or at the injury site where a neuroma forms ${ }^{4 ; 5}$. They are composed of a $\alpha$-pore forming subunit associated to one or two $\beta$-modulating subunits. Nine genes encodes for the $\alpha$-subunits, Nav1.1-1.9

Current therapy for neuropathic pain involves adjuvant medications - not primarily developed for this purpose - such as anticonvulsants, antidepressants or local anesthetics ${ }^{7}$. Tricyclic antidepressants are the most studied family of antidepressant in pain therapy and considered as first line treatment in different international guidelines ${ }^{8}$. Their mode of action does not seem to be linked to their antidepressant actions as acknowledged by their faster onset ${ }^{9}$. Among other members of that family, amitriptyline was shown to interact with sodium channels as exemplified by its cardiac toxicity and this target could also play a role in pain modulation ${ }^{10}$. Mexiletine, a sodium channel blocker and an oral analog of local anesthetics has been used in the treatment of neuropathic pain ${ }^{11}$ but its tolerance on long term therapy raises considerable questions as shown by a median discontinuation of treatment of 43 days in a recent study ${ }^{12}$. Rufinamide is an antiepileptic drug licensed for a refractory type of epilepsy in the childhood, the LennoxGastaut syndrome ${ }^{13}$. Its principal mechanism of action is considered to be inhibition of sodium channels, stabilizing its inactive form and reducing the firing of sodium dependent action potentials ${ }^{14}$. 
Since the discovery that loss-of-function mutations in $S C N 9 A$, the gene encoding for

Nav1.7 isoform, are associated with congenital insensitivity to pain ${ }^{15}$, it has become a potential target for treatment. Moreover, gain-of-function mutations SCN9A are associated with familial pain syndromes (erythromelalgia and paroxysmal extreme pain disorder reviewed by Lampert ${ }^{16}$ ) and in subset of patients with idiopathic small nerve fiber neuropathy or generalized pain syndromes ${ }^{17 ; 18}$. Nav1.7 is expressed in sensory, sympathetic and myenteric fibers ${ }^{19-21}$. It exhibits slower recovery from fast inactivation ${ }^{22 ; 23}$ compared to other tetrodotoxin-sensitive channels Nav1.4 and 1.6 and slower inactivation at potentials close to the membrane resting potential, thus contributing to the large ramp current during slow depolarization ${ }^{24}$. Nav1.7 is thought to play an important role in "boosting" the depolarization of small diameter nociceptive neurons.

In the present study, we investigated the analgesic effect of rufinamide on the spared nerve injury (SNI) model of neuropathic pain and amitriptyline was used as a positive control. Our null hypothesis was that treated and control groups show the same behavior. We also explored the effect of rufinamide on Nav1.7 channels heterogeneously expressed in human embryonic kidney 293 cells and used mexiletine and amitriptyline as control. We finally tested the effect of rufinamide on dorsal root ganglia neurons. In these electrophysiological experiments our null hypothesis was that the drugs do not change the measured parameters, which were $\mathrm{V}_{1 / 2}$ of activation and steady-state inactivation and $t_{1 / 2}$ of recovery from inactivation. 


\section{Materials \& Methods:}

\section{Drugs:}

Rufinamide (R8404), amitriptyline (A8404) and mexiletine (M2727) were purchased from Sigma (Buchs, Switzerland). For behavioral experiment, rufinamide was dissolved in dimethylsulfoxide (DMSO) and then mixed with $1 \mathrm{x}$ phosphate buffered saline to the desired concentration. Control was $30 \%$ DMSO in 1x phosphate buffered saline. Doses $(5,10,25,50 \mathrm{mg} / \mathrm{kg})$ were chosen corresponding to the therapeutic ones used in epilepsy models in mice (rufinamide was effective in the maximal electroshock test (ED $23.9 \mathrm{mg} / \mathrm{kg}$ orally) and in the pentylenetetrazol induced seizure test ( $54 \mathrm{mg} / \mathrm{kg}$, intraperitoneally $)^{25}$. Amitriptyline was dissolved directly in sterile $0.9 \%$ saline and doses were chosen according to previous studies in neuropathic pain models. Drugs were administered intraperitoneally.

Animal experiments:

All experiments were approved by the Committee on Animal Experimentation of the Canton de Vaud, Lausanne, Switzerland, in accordance with Swiss Federal law on animal care and the guidelines of the International Association for the Study of Pain ${ }^{26}$. Fiveweek-old C57BL/6 male mice (Charles River, I'Abresle, France) weighting 20-25g at the start of experiment were housed in the same room, 5 per cage, at constant temperature of $21^{\circ} \mathrm{C}$ and a $12 / 12$ dark/light cycle. No other animals were housed in that room. Mice had ad libitum access to water and food.

\section{Surgery}

SNI surgery ${ }^{27 ; 28}$ on mice ${ }^{29}$ was performed under $1.5-2.5 \%$ isoflurane (Abott AG, Baar, ZG, Switzerland) anesthesia. Briefly, the left hindlimb was immobilized in a lateral 
position and slightly elevated. Incision was made at mid-thigh level using the femur as a

landmark and a section was made through the biceps femoris in the direction of point of origin of the vascular structure. The three peripheral branches (sural, common peroneal and tibial nerves) of the sciatic nerve were exposed without stretching nerve structures. Both tibial and common peroneal nerves were ligated using a 6.0 silk suture and transected together. The sural nerve was carefully preserved by avoiding any nerve stretch or nerve contact.

\section{Behavior}

For all the behavioral experiments, the observer was blinded to the treatment applied. Mechanical sensitivity: Animals were habituated to the testing environment daily for at least 2 days before baseline testing. The room temperature and humidity remained stable for all experiments. For testing mechanical sensitivity, animals were put under inverted plastic boxes on an elevated mesh floor and allowed 10 min for habituation before the threshold testing. Mechanical allodynia was tested using a series of von Frey hairs with logarithmically incrementing stiffness $(0.02,0.04,0.08,0.16,0.32,0.64$, 1.28 , and $2.56 \mathrm{~g}$ ). The filaments were applied perpendicularly to the plantar surface $1-2$ s. The $50 \%$ withdrawal threshold was determined using Dixon's up-down method ${ }^{30}$. Heat sensitivity: The effect of rufinamide and amitriptyline on basal heat sensitivity was assessed with the Hot Plate assay. Briefly, the animals were placed on the hot-plate surface set at $52^{\circ} \mathrm{C}$. The latency of response (in seconds) was determined as the time until a hindlimb lick or jump occurred. The cutoff was set at $30 \mathrm{~s}$ to avoid tissue damage. Activity was quantified with the Activ-meter (Bioseb, France). The total activity (summation of immobile, slow and fast activity given by the software) of naive animals in their home cage was measured during the 4 hours following injection of rufinamide (50 $\mathrm{mg} / \mathrm{kg}$ ) and amitriptyline $(10 \mathrm{mg} / \mathrm{kg})$. It was compared to the activity after saline injection. All experiments for activity were performed between 5 and 9pm. 
A 5 point sedation score from $0-4$ points was used for rufinamide $(50 \mathrm{mg} / \mathrm{kg})$ and amitriptyline $(10 \mathrm{mg} / \mathrm{kg}), 0=$ normal behavior, normal locomotion, $1=$ awake, slow locomotion, 2=no locomotion, eyes half closed, still responding to righting reflex, $3=$ asleep, eyes closed, still responding to righting reflex, $4=$ no righting reflex, adapted from Boast et al. ${ }^{31}$.

\section{Experimental design}

For drug effect on naïve animals, 8 animals per group were used to assess mechanical withdrawal threshold and heat withdrawal latency. For the Activ-meter, 6 animals were used in a cross-over design for rufinamide and amitriptyline.

Normal mechanical threshold was assessed before surgery without difference between groups. SNI surgery was performed and one week later allodynia-like behavior was tested before intraperitoneal injection of rufinamide. Two series of experiments were done, the first one compared rufinamide $25 \mathrm{mg} / \mathrm{kg}$ and $50 \mathrm{mg} / \mathrm{kg}$ to DMSO $30 \%(\mathrm{n}=10$ per group, 9 for DMSO) and the second one compared rufinamide $5 \mathrm{mg} / \mathrm{kg}$ and $10 \mathrm{mg} / \mathrm{kg}$ to DMSO $30 \%$ ( $\mathrm{n}=8$ per group) at 20-40-60-120-240 min and $24 \mathrm{~h}$. After a washout period of one week the animals of the first series were tested with amitriptyline 10 or 20 $\mathrm{mg} / \mathrm{kg}$ or saline at 60-120-240 min and $24 \mathrm{~h}$ after intraperitoneal injection ( $\mathrm{n}=9$ per group for amitriptyline $20 \mathrm{mg} / \mathrm{kg}$ and 10 per group for amitriptyline $10 \mathrm{mg} / \mathrm{kg}$ and saline). Plasma levels of the drug were assessed at $120 \mathrm{~min}$ after injection of $50 \mathrm{mg} / \mathrm{kg}$ rufinamide. Mice $(n=3)$ were anesthetized with isoflurane and $1 \mathrm{ml}$ of blood was collected intracardially. Drug levels were analyzed by the pharmaceutical monitoring laboratory of Lavigny, Switzerland (http://www.ilavigny.ch/html/hopital/laboratoire.php, last accessed June $21^{\text {st }} 2012$ ).

Electrophysiology: 
Rufinamide was dissolved in DMSO at $10 \mu \mathrm{mol} / \mathrm{l}$ as stock solution and diluted daily at

desired concentration in the extracellular medium. As control the same DMSO concentration was used ( $1 \%$ for $100 \mu \mathrm{g} / \mathrm{ml}$, to $5 \%$ for $500 \mu \mathrm{g} / \mathrm{ml}$ ). Higher concentration could not be achieved without increasing DMSO content. Amitriptyline and mexiletine were dissolved in extracellular medium directly.

Human embryonic kidney 293 cells stably expressing Nav1.7 were kindly provided by Simon Tate (PhD, Chief Scientific Officer, Convergence Pharmaceuticals, Cambridge, UK) and were cultured in DMEM-F12 + L-Glutamine (Invitrogen, Merelbeke, Belgium) supplemented with $5 \%$ fetal bovine serum and geneticin $0.4 \mathrm{mg} / \mathrm{ml}$. Measurements were made at room temperature using pClamp software, version 10.2, and a VE-2 amplifier (Alembic Instruments, Montreal, Quebec, Canada). The sampling rate was $30 \mathrm{kHz}$. Data were smoothed and analyzed using Clampfit software version 10.2.0.12 (Axon Instruments, Union City, CA), and KaleidaGraph (Synergy Software, Reading, PA). Whole-cell Patch clamp recordings were conducted using an internal solution containing (in $\mathrm{mmol} / \mathrm{l}$ ) $\mathrm{CsCl} 60$, Cesium aspartate 70, EGTA 11, $\mathrm{MgCl}_{2} 1, \mathrm{CaCl}_{2} 1, \mathrm{HEPES} 10$, and $\mathrm{Na}_{2}$-ATP 5, pH adjusted to 7.2 with $\mathrm{CsOH}$; and an external solution containing $\mathrm{NaCl} 50$, n-methyl-D-glutamine- $\mathrm{Cl} 80, \mathrm{CaCl}_{2} 2, \mathrm{MgCl}_{2} 1.2, \mathrm{CsCl} 5, \mathrm{HEPES} 10$, and glucose 5, pH adjusted to 7.4 with $\mathrm{CsOH}$. Holding potential was $-100 \mathrm{mV}$. The values were not corrected for liquid junction potential. Pipette resistance was ranging from 2 to 4 MOhm. Only data from cells having stable access resistance over the duration of the experiment were used. Cells for which signs of poor voltage-clamp control, such as delayed inflections of the current or discontinuities in the peak $I_{N a}$ versus $V_{m}$ curve were not analyzed. Around $15 \%$ of sealed cells were lost. Data were filtered after acquisition using Boxcar 9 points. Peak currents were measured with a single $10 \mathrm{~ms}$ pulse protocol to $-10 \mathrm{mV}$ from the holding potential. Percentage inhibition was calculated as (peak vehicle $^{-}$ peak $\left.k_{\text {drug }}\right) /$ peak $_{\text {vehicle }} \times 100$ for each cell and then mean inhibition for each drug and 
concentration was calculated. Other protocols are shown as inserts in the figures. The linear ascending segment of the current-voltage relationship was used to estimate the reversal potential for each trace before obtaining the voltage-dependent activation curve. Voltage dependence of activation and steady state inactivation curves were individually fitted with Boltzmann relationships, $y\left(V_{m}\right)=1 /\left(1+\exp \left[\left(V_{m}-V_{1 / 2}\right) / K\right]\right)$ in which $\mathrm{y}$ is the normalized current or conductance, $\mathrm{Vm}$ is the membrane potential, $\mathrm{V}_{1 / 2}$ is the voltage at which half of the channels are activated or inactivated and $\mathrm{K}$ is the slope factor. The value of $t_{1 / 2}$ of recovery from inactivation was calculated by interpolation from a linear relation between the 2 points juxtaposing half recovery $\left(y_{1}<0.5<y_{2}\right)$, using the relation $x=\left[0.5-\left(y_{1} x_{2}-y_{2} x_{1}\right) /\left(x_{2}-x_{1}\right)\right] *\left(x_{2}-x_{1}\right) /\left(y_{2}-y_{1}\right)$. For use-dependent block, the percentage of decrease of current was calculated between the $1^{\text {st }}$ and $50^{\text {th }}$ pulse. For ex-vivo recordings, dorsal root ganglion neurons were collected from adult C57BL/6 mice (4-8 weeks old). Briefly, L4 and L5 dorsal root ganglion neurons were harvested and digested in Liberase blendzyme TM (Roche, Indianapolis, USA) $0.5 \mathrm{U} /$ dorsal root ganglion with $12 \mu \mathrm{M}$ EDTA in $5 \mathrm{ml}$ Complete Saline Solution (in $\mathrm{mmol} / \mathrm{l}, \mathrm{NaCl} 137, \mathrm{KCl}$ 5.3, $\mathrm{MgCl} 2-6 \mathrm{H} 2 \mathrm{O}$ 1, Sorbitol 25, HEPES 10, $\mathrm{CaCl} 23$ and $\mathrm{pH}$ adjusted to 7.2 with $\mathrm{NaOH}$ ) for $20 \mathrm{~min}$ at $37^{\circ} \mathrm{C}$. Neurons were further digested with Liberase blendzyme TL with EDTA in Complete Saline Solution with papaïn $(30 \mathrm{U} / \mathrm{ml})$ for $10 \mathrm{~min}$. Finally neurons were suspended in dorsal root ganglion medium mix (89\% DMEM/F-12, $10 \%$ BSA, $1 \%$ penicillin/streptomycin) supplemented with $1.5 \mathrm{mg} / \mathrm{ml}$ of trypsin inhibitor and $1.5 \mathrm{mg} / \mathrm{ml}$ of purified BSA. Mechanical dissociation was performed using a pipetman and neurons were plated on poly-D-lysine coated coverslips and incubated 12 hours before recording to allow recovery and adhesion of neurons. Neurons were only recorded for 12 more hours to prevent long-term culture phenotypic changes and neurite outgrowth that degrades space clamp. Small neurons (diameter $<30 \mu \mathrm{m}$ ) were recorded using an EPC-10 amplifier (HEKA Electronics, Lambrecht, Germany) and Patchmaster/Fitmaster software 
for data acquisition/analysis. The sampling interval was $20 \mu$ s and a $5 \mathrm{kHz}$ filter was used configuration. Extracellular solution contained (in mmol/l) $\mathrm{NaCl} 30, \mathrm{TEA}-\mathrm{Cl} 110, \mathrm{KCl} 3$, $\mathrm{CaCl}_{2} 1, \mathrm{MgCl}_{2} 1$, HEPES 10 , Glucose $10, \mathrm{CdCl} 0.1 ; \mathrm{pH}$ was adjusted to 7.3 using Tris base, osmolarity was adjusted to $320 \mathrm{mosm} / \mathrm{l}$ with sucrose. The pipette solution contained $\mathrm{CsF}$ 140, $\mathrm{NaCl} 10, \mathrm{MgCl}_{2} 2, \mathrm{CaCl}_{2}$ 0.1, EGTA 1.1, HEPES 10, pH was adjusted to 7.2 with $\mathrm{CsOH}$ and osmolarity was adjusted to $310 \mathrm{mosm} / \mathrm{l}$. Pipettes were pulled from Borosilicate glass (World Precision Instruments, Sarasota, FL, USA) and had a resistance $<3 \mathrm{M} \Omega$, when filled with the pipette solution. Capacity transients were cancelled and series resistance was compensated to around $90 \%$. Leakage current was digitally subtracted online using hyperpolarizing control pulses, applied after the test pulse, of one-fourth test pulse amplitude ( $\mathrm{P} / 4$ procedure). For current density measurements, membrane currents were normalized to the membrane capacitance which was calculated from the integral of the transient current in response to a brief hyperpolarizing pulse of $10 \mathrm{mV}$ from the holding potential.

Once in whole cell configuration, cells were held at $-60 \mathrm{mV}$ for 5 minutes to dialyze the cell with CsF solution (fluoride shifts Nav1.8 steady-state activation and inactivation to hyperpolarized potentials) to reach Nav1.8 stable biophysical properties and to inactivate Nav1.9 current and was further clamped at $-80 \mathrm{mV}$ for 2 more minutes. Whole-cell $\mathrm{Na}$ currents were elicited by a series of 100 ms test pulses ranging from $-80 \mathrm{mV}$ to $+40 \mathrm{mV}$ in increments of $5 \mathrm{mV}$ at a frequency of $0.33 \mathrm{~Hz}$. Test pulses were preceded by a prepulse of $3 \mathrm{~s}$ at $-120 \mathrm{mV}$. Normalized conductance (G/Gmax) was fitted as described for in vitro recordings and $V_{1 / 2}$ and slope factor were extracted from the equation. Steady state inactivation curves (SSI) were measured from a holding potential of $-120 \mathrm{mV}$ using $500 \mathrm{~ms}$ prepulses to the indicated potentials followed by a test pulse to $0 \mathrm{mV}$. Again, $\mathrm{V}_{1 / 2}$ and slope factors were obtained as mentioned for in vitro recordings. 
Recovery from inactivation curves were obtained with a standard two-pulse protocol consisting of a depolarizing pulse from a holding potential of $-120 \mathrm{mV}$, to $0 \mathrm{mV}$ for $50 \mathrm{~ms}$ to inactivate the channels, followed by a variable duration step (from $0.05 \mathrm{~ms}$ to 3276.8 $\mathrm{ms}$ ) back to $-120 \mathrm{mV}$ to promote recovery. The availability of the channels was assessed with a second test pulse at $0 \mathrm{mV}$ and the ratio of the second pulse versus the first was plotted against the recovery interval. The $t_{1 / 2}$ of recovery was calculated as mentioned previously.

\section{Statistics:}

-Behavioral statistics: For the time course and drug effect on mechanical allodynia after nerve injury 3 experiments were done separately: i) rufinamide $25 \mathrm{mg} / \mathrm{kg}$, rufinamide $50 \mathrm{mg} / \mathrm{kg}$ and DMSO30\%, ii) rufinamide $5 \mathrm{mg} / \mathrm{kg}$, rufinamide $10 \mathrm{mg} / \mathrm{kg}$ and DMSO30\%, iii) amitriptyline $10 \mathrm{mg} / \mathrm{kg}$, amitriptyline $20 \mathrm{mg} / \mathrm{kg}$ and saline. The log values of withdrawal thresholds were assessed for each experiment using an Anova two-ways with Bonferroni correction for repeated measures from preinjection to $24 \mathrm{~h}$ after injection. For the development of allodynia, baseline and preinjection were compared by using the Wilcoxon matched-pairs signed rank test (Bonferroni's correction for multiple testing) because baseline values are skewed. For clarity purposes on figure 1, a mean value of both DMSO groups is used and values are presented as mean \pm SD also for baseline. For the drug effect on naïve animals, data were analyzed with Kruskal-Wallis test and Dunn's correction for multiple testing. The numerical data are presented as median with $95 \%$ confidence interval.

-Electrophysiological statistics: Data are presented as mean \pm SD and were analyzed using paired student's $t$ tests for drug effect.

All hypotheses were challenged using two-tailed testing and $p<0.05$ was used as the level of significance. Statistical analysis was performed using Prism 5 for windows, version 5.03, GraphPad Software, San Diego California USA. 


\section{Results:}

\section{Behavior}

1.1 Rufinamide reduces mechanical allodynia following SNI

All animals developed allodynia one week after surgery $(p<0.05$, preinjection versus baseline for all groups). Rufinamide significantly and dose dependently alleviated SNIinduced allodynia (Fig. 1A), with maximal effect from $0.10 \pm 0.03 \mathrm{~g}$ (mean \pm SD) to $1.99 \pm 0.26 \mathrm{~g}$. The effect was seen already 20 minutes following injection, peaked at 60 min, lasted for at least 4 hours, but had faded 24 hours after drug administration. At the highest dose of rufinamide, allodynia-like behavior was completely reversed. The vehicle DMSO showed a tendency for anti-allodynic effect but the values did not reach statistical significance in multiple testing.

\subsection{Amitriptyline reduces mechanical allodynia following SNI}

All animals showed allodynia before injection of amitriptyline $(p<0.05$ preinjection versus baseline for all groups). Amitriptyline alleviated the allodynic behavior from 60 to 240 min after injection and the effect had disappeared at 24h (Fig. 1B) with maximal effect from $0.25 \pm 0.22 \mathrm{~g}$ to $1.9 \pm 0.8 \mathrm{~g}$. There was no difference between 10 and $20 \mathrm{mg} / \mathrm{kg}$.

\subsection{Amitriptyline but not rufinamide affects basal sensitivity}

Rufinamide $(50 \mathrm{mg} / \mathrm{kg}$ ) did not modify basal mechanical sensitivity of naive animals or heat withdrawal latency. We therefore did not test lower doses (Fig. 2A-B). On the other hand, amitriptyline at $20 \mathrm{mg} / \mathrm{kg}$ increased withdrawal threshold for innocuous mechanical stimulation with von Frey hair from 1.3g (0.6-1.9) (median and 95\% confidence interval) to $2.3 \mathrm{~g}(2.2-2.5)$ and increased withdrawal latency on heat stimulation compared to saline from 13.1s (10.4-15.5) (median, 95\%CI) to 30.0s (21.8-31.9). We therefore tested amitriptyline at $10 \mathrm{mg} / \mathrm{kg}$ and also observed antinociceptive effect on heat 
stimulation (withdrawal threshold from $10.5 \mathrm{~s}(7.2-11.7)$ to $25.3 \mathrm{~s}(16.4-27.7)$ ), but no statistically significant difference on non-noxious mechanical stimulation (Fig. 2A-B). Animals injected with rufinamide $50 \mathrm{mg} / \mathrm{kg}$ did not lower their total activity measured over 4 hours after injection with the Activ-meter as compared to saline injected controls. Amitriptyline decreased total activity statistically significantly compared to saline injected controls (Fig. 2C).

Amitriptyline increased the score of sedation from 0 (saline group) to 2[0-3] (median, [range], $n=8)$. Rufinamide did not change the score (0).

1.4 Rufinamide plasma level corresponds to therapeutic level for epileptic patients At peak effect for mechanical allodynia, the range of plasma level for rufinamide was 68$86 \mu \mathrm{mol} / \mathrm{l}$.

2. Effect of rufinamide on Nav1.7 channel compared to amitriptyline and mexiletine 2.1 Rufinamide reduces Nav1.7 peak current Rufinamide reduced peak sodium current (INa) induced by a single pulse depolarization using human embryonic kidney 293 cells stably expressing Nav1.7 (Fig. 3). The most substantial reduction obtained with rufinamide was $28.3 \%$, at a concentration of 500 $\mu \mathrm{mol} / \mathrm{l}$. The drug could not be dissolved at higher concentration. A concentration of 100 $\mu \mathrm{mol} / \mathrm{I}$ was used for the rest of the testing to avoid the high DMSO concentration used for $500 \mu \mathrm{mol} / \mathrm{l}$. With high concentration of amitriptyline and mexiletine a complete inhibition of $\mathrm{I}_{\mathrm{Na}}$ could be obtained and EC50 were used for the following experiments (Fig. 3).

\subsection{Rufinamide shifts steady-state inactivation of Nav1.7}

The voltage dependence of activation was examined using a series of $10 \mathrm{~ms}$ depolarizing test pulses from -80 to $+85 \mathrm{mV}$ from a holding potential of $-100 \mathrm{mV}$. Rufinamide had no 
effect on voltage-dependency of activation for Nav1.7 sodium channel, nor did amitriptyline and mexiletine. No statistically significant changes were seen in $V_{1 / 2}$ of activation. Slopes were slightly altered by rufinamide and mexiletine (Fig. 4). For the steady-state inactivation experiments, cells were given a 500 ms conditioning pulse at voltages between $-130 \mathrm{mV}$ and $-10 \mathrm{mV}$ from a holding potential of $-100 \mathrm{mV}$ followed by a 20 ms test pulse. Normalized sodium currents ( $I_{\mathrm{Na}} / \mathrm{Imax}$ ) measured during test pulses were plotted against conditioning voltage. Rufinamide shifted the steady-state inactivation relationship to more hyperpolarized value with a $V_{1 / 2}$ of inactivation shifting from $-81.0 \pm 4.4$ to $-87.6 \pm 4.9 \mathrm{mV}$. The control drugs had a similar effect with shift of $\mathrm{V}_{1 / 2}$ of inactivation, from $-81.8 \pm 2.8$ to $-88.4 \pm 1.1 \mathrm{mV}$ for amitriptyline and from $-80.0 \pm 3.0$ to $-91.4 \pm 2.6 \mathrm{mV}$ for mexiletine. The slopes of steady-state inactivation curves were not influenced by any of the tested drugs (Fig. 4).

\subsection{Rufinamide prolongs the recovery from fast inactivation of Nav1.7}

Effects on the recovery from fast inactivation was examined with a standard double-pulse protocol consisting of a depolarizing pulse to $-10 \mathrm{mV}$ to inactivate the channels followed by a variable duration ( 0.25 to $2000 \mathrm{~ms}$ ) step to the holding potential of $-100 \mathrm{mV}$ to promote recovery. The availability of the channels at the end of the recovery interval was assessed with a standard test pulse. The ratios of response of $2^{\text {nd }} / 1^{\text {st }}$ pulse were plotted versus the recovery interval. The $t_{1 / 2}$ of recovery was interpolated. It was statistically significantly prolonged for the 3 tested drugs (Fig. 5).

\subsection{Rufinamide shows use-dependent inhibition of Nav1.7}

Frequency-dependent or use-dependent blocking refers to the accumulation of channels in inactivated state when subjected to a train of depolarizing pulses at high frequency. We applied a series of 50 pulses at varying frequencies $(2,5,10,25,50 \mathrm{~Hz})$ and plotted 
the normalized current against the pulse number. Rufinamide at $100 \mu \mathrm{mol} / \mathrm{l}$ increased the use-dependent block at all frequencies tested, except $2 \mathrm{~Hz}$. Amitriptyline and mexiletine also increased the use-dependent block, even at $2 \mathrm{~Hz}$ (Fig. 6).

\section{Rufinamide influences INa in dorsal root ganglion neurons}

We then wanted to validate the effect of rufinamide using dissociated mouse dorsal root ganglion neurons which contain also other Nav channels and the $\beta$-subunits. We first observed that rufinamide at $100 \mu \mathrm{mol} / \mathrm{l}$ consistently induced a statistically significant $10.1 \%$ mean reduction in peak sodium current densities from $956 \pm 396$ to $850 \pm 339$ $\mathrm{pA} / \mathrm{pF}(\mathrm{p}<0.05)$ despite a great variability in absolute values of current density (Fig. $7 \mathrm{~A})$. We then assessed voltage-dependence of activation and inactivation of the sodium current on the dorsal root ganglion with step protocols. The global effect of rufinamide on dorsal root ganglion was similar to the one observed using human embryonic kidney 293 cells expressing only Nav1.7. The voltage-dependence of activation was unchanged and the inactivation curve was shifted with statistical significance toward more hyperpolarized potentials, from a $V_{1 / 2}$ of inactivation of $-64.4 \pm 16.8 \mathrm{mV}$ to-69.4 $\pm 17.1 \mathrm{mV}(\mathrm{p}<0.0001)$ (Fig. 7B). Finally we observed that rufinamide also delayed $t_{1 / 2}$ of recovery from inactivation from $2.58 \pm 2.12$ to $6.24 \pm 5.04 \mathrm{~ms}(p<0.05)$ (Fig. 7C). 


\section{Discussion:}

We here demonstrate that rufinamide alleviates mechanical allodynia-like behavior in the SNI model of neuropathic pain in mice. Its effect is comparable to amitriptyline, but with no interference on basal sensitivity and activity tests. We also show that rufinamide modulates Nav1.7. It stabilizes the channel in its inactivated state similarly to amitriptyline and mexiletine, and delays its recovery from inactivation. By the observation of rufinamide effect on total sodium currents recorded in dorsal root ganglion neurons, we finally validated a potential peripheral mechanism of action of rufinamide for the treatment of neuropathic pain.

\section{Effect of rufinamide on mechanical allodynia following SNI in mice}

We present a robust effect of amitriptyline and rufinamide on SNI-induced mechanicalallodynia in mice. To our knowledge, this is the first trial testing rufinamide in a model of neuropathic pain.

Amitriptyline is a first line treatment for clinical neuropathic pain ${ }^{8}$. Amitriptyline alleviates neuropathic pain-like behavior in the chronic constriction injury ${ }^{32 ; 33}$ and spinal nerve ligation models ${ }^{34}$. In other studies it failed to affect mechanical allodynia in these models $s^{35 ; 36}$ or on paw pressure hypersensitivity in a rat diabetes-related pain model ${ }^{37}$. In the SNI model, in rats, amitriptyline decreased mechanical allodynia in the early 3-5 days post injury ${ }^{38}$ whereas it failed to show an effect 2 to 4 weeks after nerve injury ${ }^{39}$. When administered perisurgically for 1 week, amitriptyline failed to prevent the development of mechanical allodynia in rodents ${ }^{40}$.

Despite diverging results explained by the different sensory modalities tested, timing, dose and administration route or species/genetic background ${ }^{41 ; 42}$, the SNI model remains a robust neuropathic pain model in rodents. In rats, mechanical allodynia following SNI 
does not respond to moderate doses of morphine, gabapentin, carbamazepine, MK- $801^{39}$, lidocaine, lamotrigine ${ }^{43}$ or rofecoxib ${ }^{44}$. Other groups showed a transient effect of high dose of morphine ( $6 \mathrm{mg} / \mathrm{kg}$, effect $<3$ hours), mexiletine ( $37 \mathrm{mg} / \mathrm{kg},<1$ hour) or gabapentin $(100 \mathrm{mg} / \mathrm{kg},<5 \text { hours })^{45}$ and tocainide ${ }^{43}$. Side effects and sedation are rarely mentioned but with high doses, many of the tested drugs in SNI could impair basal sensitivity ${ }^{39}$.

Rufinamide alleviates dose-dependently mechanical allodynia in this model, without inducing any changes in sedation or affecting basal sensitivity. Amitriptyline reduced allodynia, but also modified basal pain sensitivity and sedation score, which could participate in its anti-allodynic effect. Amitriptyline has been shown previously to change locomotor activity in rodents due to sedation, ataxia, changes in nociception, depression or anxiety ${ }^{46-50}$. In one study amitriptyline did not change locomotor activity in the chronic constriction injury model despite reducing allodynia. We are in agreement with others who showed an increase in thermal latency after acute amitriptyline treatment ${ }^{46 ; 51}$. Rufinamide has the potential of a new treatment for neuropathic pain As first line therapy for the treatment of neuropathic pain, clinical guidelines propose tricyclic antidepressants (amitriptyline), serotonin and norepinephrine reuptake inhibitors (duloxetine and venlafaxine) or anticonvulsants targeting a2- $\delta$ subunit of calcium channels (gabapentin and pregabalin) ${ }^{8 ; 52}$. The most effective antidepressants in the treatment of neuropathic pain have sodium channel blocking properties ${ }^{53}$, which may contribute to their analgesic activity ${ }^{10 ; 54}$. The use of sodium channel blockers as a firstline evidence-based treatment recommendation has not yet been suggested except for two specific conditions: carbamazepine in trigeminal neuralgia ${ }^{52}$ and topical lidocaine in postherpetic neuralgia with irritable nociceptor ${ }^{11}$. The systemic delivery of a sodium channel blocker is limited by the poor tolerability (and restricted availability in many countries) of mexiletine as well as the high risk of drug interaction with carbamazepine ${ }^{55}$. 
Rufinamide offers a valuable alternative to tricyclic antidepressants / serotonin and norepinephrine reuptake inhibitors and calcium channel a2- $\delta$ ligand for the pharmacologic management of neuropathic pain.

In clinical practice, the efficacy of amitriptyline on neuropathic pain is variable ${ }^{56 ; 57}$. Amitriptyline is well known for its side effects, predominantly sedation, hypotension and anti-cholinergic effects, considerably reducing patient's compliance ${ }^{58}$. In particular, sedation has been known for a long time even at "light" dosage $(50 \mathrm{mg})^{59 ; 60}$. For rufinamide, in a study for Lennox-Gastaut syndrome, the incidence of adverse events for somnolence or vomiting was more common in the rufinamide treated group ${ }^{13}$, but causing only 2 respectively 3 patients out of 74 to withdraw from the study. Drug interaction is also a major issue for pain therapy. Rufinamide presents favorable pharmacokinetic parameters; it is well absorbed orally and is not a substrate of cytochrome p450 system, thereby reducing its potential interactions. It is however a mild inducer of CYP3A $4{ }^{61}$. Rufinamide may be a mood-stabilizing molecule with anxiolytic properties $^{62}$ that could be an added value considering the large proportion of psychiatric mood-disorders encountered in chronic pain patients ${ }^{63}$. The toxicity studies in rodents show a greater safety ratio than other anticonvulsants ${ }^{25}$. Na channels are still a major target in the development of new analgesic drugs ${ }^{23 ; 64}$, but rufinamide already being on the market, might offer a new treatment opportunity in the pain field, while other drugs trying their way through clinical trials have failed ${ }^{65 ; 66}$.

\section{Site of action of Rufinamide}

Rufinamide is a sodium channel blocker but its exact mechanism and site of action are unknown. Its effects on biophysical properties of sodium currents are similar to amitriptyline and mexiletine. Amitriptyline apparently interacts with residues on the 
DIVS6 segment ${ }^{67}$ but also DIS6, DIIIS6 and DIVS6 segments, which may jointly form parts of the amitriptyline/local anesthetic receptor ${ }^{68}$.

The importance of DIVS6 segment in mexiletine binding to sodium channel has also been demonstrated ${ }^{69}$. Further studies are needed to investigate the site of action of rufinamide on Nav1.7 and other channel isoforms, but a similar site can be hypothesized from the properties of stabilization of the inactivated state shown here. Following the recent report of the crystal structure of the voltage-gated sodium channel we hope new mechanistic knowledge will be gained in drug-channel interactions ${ }^{70}$.

We demonstrated the action of rufinamide on the peripherally expressed Nav1.7 isoform of sodium channel but we do not intend to show any specific Nav1.7 blocking properties. Indeed the drug is used in the treatment of epilepsy and therefore should also act on centrally expressed sodium channels. Rufinamide showed no relevant interaction with monoaminergic binding sites in radioligand binding studies and no interactions with benzodiazepine or gamma-aminobutyric acid (GABA) receptors, $5-\mathrm{HT} 1$ and $5 \mathrm{HT} 2$ receptors, a- or $\beta$-adrenoceptors, or human recombinant metabotropic glutamate receptor subtypes $1 b, 2$, or 4 (mGluR1b, mGluR2, mGluR4). However, an inhibitory effect of rufinamide at the mGluR5 subtype was observed at $100 \mu \mathrm{mol} /{ }^{61}$. mGluR5 is upregulated in the dorsal root ganglia and spinal cord after spinal nerve ligation (but not after partial sciatic nerve ligation $)^{71}$ and peripheral mGluR5 agonists can produce thermal hyperalgesia ${ }^{72}$. Trials on mGluR5 antagonists mostly show an effect on thermal sensitivity in neuropathic pain models but not on mechanical allodynia ${ }^{71 ; 3}$. Some groups show an effect on spinal nerve ligation model or chronic constriction injury in rats ${ }^{74}$, but the magnitude of effect on mechanical allodynia is below $40 \%$ of recovery toward baseline values for systemic administration. Dogrul et al showed a $66 \%$ reduction in mechanical allodynia with a shallow dose-response curve following spinal nerve ligation after intrathecal delivery of mGluR5 antagonist ${ }^{75}$. Fisher et al could show a preventive effect 
when an antagonist of mGluR5 was administered over 8 days after constriction injury of

\section{Limitations of the study}

Differential effect of Rufinamide, amitriptyline and mexiletine on Nav1.7 sodium channel We used the ED50 of amitriptyline and mexiletine, $10 \mu \mathrm{M}$ and $100 \mu \mathrm{M}$ respectively. The plasma concentrations of these 2 drugs are typically around $0.3 \mu \mathrm{mol} / \mathrm{I}^{78}$ and $2.3-9.3$ $\mu \mathrm{mol} / \mathrm{I}^{58}$. Rufinamide was used at $100 \mu \mathrm{mol} / \mathrm{l}$, due to its low solubility in patch clamp solution. Our study is not intended to compare the effect size of the drugs on the different biophysical properties. The low solubility of rufinamide impeded a comparison of the 3 drugs at their ED50 values. The effect on peak current on Nav1.7 as well as on 
dorsal root ganglion neurons is low but nonetheless statistically significant and reproducible.

\section{Effect of DMSO as control}

DMSO was used to dissolve rufinamide despite the potential neurotoxicity with prolonged administration at high dose ${ }^{79}$. It was also used as a treatment option in osteoarthritis ${ }^{80}$ but only with relative efficacy on pain scores. We did not see any effect of DMSO on naïve animal sensitivity behavior regarding toxicity and compared the anti-allodynic of rufinamide to DMSO.

\section{Conclusion and future directions}

We here show that rufinamide dose-dependently alleviates neuropathic pain behavior in the SNI model in mice. We show in vitro electrophysiological data that rufinamide induces a hyperpolarizing shift in the steady-state inactivation curve, a use dependentblock and a delay in recovery from inactivation from Nav1.7-mediated current and exvivo data that the same stabilizing effect on inactivation is also present in dorsal root ganglion neurons. Sodium channels blockers still belong to the potential targets to treat neuropathic pain but often do not come on the market for toxicity or side effects issues. Rufinamide is currently on the market and could therefore be used in clinical studies in the pain field rapidly. With the low rate of success from current chronic pain therapy, a new drug would be highly valued. 
Reference List

1. Breivik H, Collett B, Ventafridda V, Cohen R, Gallacher D: Survey of chronic pain in Europe: Prevalence, impact on daily life, and treatment. Eur J Pain 2006; 10: 287-333

2. Dib-Hajj SD, Cummins TR, Black JA, Waxman SG: Sodium channels in normal and pathological pain. Annu Rev Neurosci 2010; 33: 325-47

3. Berta T, Poirot O, Pertin M, Ji RR, Kellenberger S, Decosterd I: Transcriptional and functional profiles of voltage-gated $\mathrm{Na}(+)$ channels in injured and non-injured DRG neurons in the SNI model of neuropathic pain. Mol Cell Neurosci 2008; 37: 196-208

4. Suter MR, Siegenthaler A, Decosterd I, Ji RR: Perioperative nerve blockade: Clues from the bench. Anesthesiol Res Pract 2011; 124898:

5. Devor M: Responses of nerves to injury in relation to neuropathic pain, Textbook of Pain, fifth edition edition. Edited by McMahon SB, Koltzenburg M. Elsevier, 2006, pp 905-28

6. Catterall WA, Goldin AL, Waxman SG: International Union of Pharmacology. XLVII. Nomenclature and structure-function relationships of voltage-gated sodium channels. Pharmacol Rev 2005; 57: 397-409

7. Besson M, Piguet V, Dayer P, Desmeules J: New approaches to the pharmacotherapy of neuropathic pain. Expert Review of Clinical Pharmacology 2008; 1: 683-93 
8. Freynhagen R, Bennett MI: Diagnosis and management of neuropathic pain. BMJ 2009; 339: b3002

9. Saarto T, Wiffen P: Antidepressants for neuropathic pain. Cochrane Database Syst Rev 2007; CD005454

10. Dick IE, Brochu RM, Purohit Y, Kaczorowski GJ, Martin WJ, Priest BT: Sodium channel blockade may contribute to the analgesic efficacy of antidepressants. J Pain 2007; 8: 315-24

11. Challapalli V, Tremont-Lukats IW, McNicol ED, Lau J, Carr DB: Systemic administration of local anesthetic agents to relieve neuropathic pain. Cochrane Database Syst Rev 2005; CD003345

12. Carroll IR, Kaplan KM, Mackey SC: Mexiletine therapy for chronic pain: Survival analysis identifies factors predicting clinical success. J Pain Symptom Manage 2008; 35: 321-6

13. Glauser T, Kluger G, Sachdeo R, Krauss G, Perdomo C, Arroyo S: Rufinamide for generalized seizures associated with Lennox-Gastaut syndrome. Neurology 2008; 70: 1950-8

14. McLean MJ, Schmutz M, Pozza M, Wamil A: The influence of rufinamide on sodium currents and action potential firing in rodent neurons. Epilepsia 2005; 46 suppl.8: 296

15. Cox JJ, Reimann F, Nicholas AK, Thornton G, Roberts E, Springell K, Karbani G, Jafri H, Mannan J, Raashid Y, Al-Gazali L, Hamamy H, Valente EM, Gorman S, Williams R, McHale DP, Wood JN, Gribble FM, Woods CG: An SCN9A channelopathy causes congenital inability to experience pain. Nature 2006; 444: 894-8

16. Lampert A, O'Reilly AO, Reeh P, Leffler A: Sodium channelopathies and pain. Pflugers Arch 2010; 460: 249-63 
17. Faber CG, Hoeijmakers JG, Ahn HS, Cheng X, Han C, Choi JS, Estacion M, Lauria G, Vanhoutte EK, Gerrits MM, Dib-Hajj S, Drenth JP, Waxman SG, Merkies IS: Gain of function Na(V) 1.7 mutations in idiopathic small fiber neuropathy. Ann Neurol 2012; 71: 26-39

18. Dabby R, Sadeh M, Gilad R, Lampl Y, Cohen S, Inbar S, Leshinsky-Silver E: Chronic nonparoxysmal neuropathic pain - Novel phenotype of mutation in the sodium channel SCN9A gene. J Neurol Sci 2011; 301: 90-2

19. Black JA, Dib-Hajj S, McNabola K, Jeste S, Rizzo MA, Kocsis JD, Waxman SG: Spinal sensory neurons express multiple sodium channel alpha-subunit mRNAs. Brain Res Mol Brain Res 1996; 43: 117-31

20. Sangameswaran L, Fish LM, Koch BD, Rabert DK, Delgado SG, Ilnicka M, Jakeman LB, Novakovic S, Wong K, Sze P, Tzoumaka E, Stewart GR, Herman RC, Chan H, Eglen RM, Hunter JC: A novel tetrodotoxin-sensitive, voltage-gated sodium channel expressed in rat and human dorsal root ganglia. J Biol Chem 1997; 272: 14805-9

21. Toledo-Aral JJ, Moss BL, He ZJ, Koszowski AG, Whisenand T, Levinson SR, Wolf JJ, SilosSantiago I, Halegoua S, Mandel G: Identification of PN1, a predominant voltage-dependent sodium channel expressed principally in peripheral neurons. Proc Natl Acad Sci U S A 1997; 94: $1527-32$

22. Herzog RI, Cummins TR, Ghassemi F, Dib-Hajj SD, Waxman SG: Distinct repriming and closedstate inactivation kinetics of Nav1.6 and Nav1.7 sodium channels in mouse spinal sensory neurons. J Physiol 2003; 551: 741-50 
23. Cummins TR, Sheets PL, Waxman SG: The roles of sodium channels in nociception: Implications for mechanisms of pain. Pain 2007; 131: 243-57

24. Cummins TR, Howe JR, Waxman SG: Slow closed-state inactivation: A novel mechanism underlying ramp currents in cells expressing the hNE/PN1 sodium channel. J Neurosci 1998; 18: $9607-19$

25. White HS, Franklin MR, Kupferberg HJ, Schmutz M, Stables JP, Wolf HH: The anticonvulsant profile of rufinamide (CGP 33101) in rodent seizure models. Epilepsia 2008; 49: 1213-20

26. Zimmermann M: Ethical guidelines for investigations of experimental pain in conscious animals. Pain 1983; 16: 109-10

27. Decosterd I, Woolf CJ: Spared nerve injury: An animal model of persistent peripheral neuropathic pain. Pain 2000; 87: 149-58

28. Suter MR, Papaloizos M, Berde CB, Woolf CJ, Gilliard N, Spahn DR, Decosterd I: Development of neuropathic pain in the rat spared nerve injury model is not prevented by a peripheral nerve block. Anesthesiology 2003; 99: 1402-8

29. Bourquin AF, Suveges M, Pertin M, Gilliard N, Sardy S, Davison AC, Spahn DR, Decosterd I: Assessment and analysis of mechanical allodynia-like behavior induced by spared nerve injury (SNI) in the mouse. Pain 2006; 122: 14

30. Chaplan SR, Bach FW, Pogrel JW, Chung JM, Yaksh TL: Quantitative assessment of tactile allodynia in the rat paw. J Neurosci Methods 1994; 53: 55-63 
31. Boast CA, Pastor G, Gerhardt SC, Hall NR, Liebman JM: Behavioral tolerance and sensitization to CGS 19755, a competitive N-methyl-D-aspartate receptor antagonist. J Pharmacol Exp Ther 1988; 247: 556-61

32. Ardid D, Guilbaud G: Antinociceptive effects of acute and 'chronic' injections of tricyclic antidepressant drugs in a new model of mononeuropathy in rats. Pain 1992; 49: 279-87

33. Yasuda T, Iwamoto T, Ohara M, Sato S, Kohri H, Noguchi K, Senba E: The novel analgesic compound OT-7100 (5-n-butyl-7-(3,4,5-trimethoxybenzoylamino)pyrazolo[1,5-a]pyrimid ine) attenuates mechanical nociceptive responses in animal models of acute and peripheral neuropathic hyperalgesia. Jpn J Pharmacol 1999; 79: 65-73

34. Abdi S, Lee DH, Chung JM: The anti-allodynic effects of amitriptyline, gabapentin, and lidocaine in a rat model of neuropathic pain. Anesth Analg 1998; 87: 1360-6

35. Esser MJ, Chase T, Allen GV, Sawynok J: Chronic administration of amitriptyline and caffeine in a rat model of neuropathic pain: Multiple interactions. Eur J Pharmacol 2001; 430: 211-8

36. Pradhan AA, Yu XH, Laird JM: Modality of hyperalgesia tested, not type of nerve damage, predicts pharmacological sensitivity in rat models of neuropathic pain. Eur J Pain 2010; 14: 503-9

37. Courteix C, Bardin M, Chantelauze C, Lavarenne J, Eschalier A: Study of the sensitivity of the diabetes-induced pain model in rats to a range of analgesics. Pain 1994; 57: 153-60

38. Mao QX, Yang TD: Amitriptyline upregulates EAAT1 and EAAT2 in neuropathic pain rats. Brain Res Bull 2010; 81: 424-7 
39. Decosterd I, Allchorne A, Woolf CJ: Differential analgesic sensitivity of two distinct neuropathic pain models. Anesth Analg 2004; 99: 457-63

40. Arsenault A, Sawynok J: Perisurgical amitriptyline produces a preventive effect on afferent hypersensitivity following spared nerve injury. Pain 2009; 146: 308-14

41. Rode F, Thomsen M, Brolos T, Jensen DG, Blackburn-Munro G, Bjerrum OJ: The importance of genetic background on pain behaviours and pharmacological sensitivity in the rat spared serve injury model of peripheral neuropathic pain. Eur J Pharmacol 2007; 564: 103-11

42. Hama AT, Borsook D: The effect of antinociceptive drugs tested at different times after nerve injury in rats. Anesth Analg 2005; 101: 175-9

43. Erichsen HK, Hao JX, Xu XJ, Blackburn-Munro G: A comparison of the antinociceptive effects of voltage-activated $\mathrm{Na}+$ channel blockers in two rat models of neuropathic pain. Eur J Pharmacol 2003; 458: 275-82

44. Broom DC, Samad TA, Kohno T, Tegeder I, Geisslinger G, Woolf CJ: Cyclooxygenase 2 expression in the spared nerve injury model of neuropathic pain. Neuroscience 2004; 124 : $891-900$

45. Erichsen HK, Blackburn-Munro G: Pharmacological characterisation of the spared nerve injury model of neuropathic pain. Pain 2002; 98: 151-61

46. Rojas-Corrales MO, Casas J, Moreno-Brea MR, Gibert-Rahola J, Mico JA: Antinociceptive effects of tricyclic antidepressants and their noradrenergic metabolites. Eur Neuropsychopharmacol 2003; 13: 355-63 
47. Matson DJ, Broom DC, Carson SR, Baldassari J, Kehne J, Cortright DN: Inflammation-induced reduction of spontaneous activity by adjuvant: A novel model to study the effect of analgesics in rats. J Pharmacol Exp Ther 2007; 320: 194-201

48. Enginar N, Hatipoglu I, Firtina M: Evaluation of the acute effects of amitriptyline and fluoxetine on anxiety using grooming analysis algorithm in rats. Pharmacol Biochem Behav 2008; 89: 450-5

49. Ogren SO, Cott JM, Hall H: Sedative/anxiolytic effects of antidepressants in animals. Acta Psychiatr Scand Suppl 1981; 290: 277-88

50. Brocco M, Dekeyne A, Veiga S, Girardon S, Millan MJ: Induction of hyperlocomotion in mice exposed to a novel environment by inhibition of serotonin reuptake. A pharmacological characterization of diverse classes of antidepressant agents. Pharmacol Biochem Behav 2002; 71: $667-80$

51. Paudel KR, Das BP, Rauniar GP, Sangraula H, Deo S, Bhattacharya SK: Antinociceptive effect of amitriptyline in mice of acute pain models. Indian J Exp Biol 2007; 45: 529-31

52. Dworkin RH, O'Connor AB, Backonja M, Farrar JT, Finnerup NB, Jensen TS, Kalso EA, Loeser JD, Miaskowski C, Nurmikko TJ, Portenoy RK, Rice AS, Stacey BR, Treede RD, Turk DC, Wallace MS: Pharmacologic management of neuropathic pain: Evidence-based recommendations. Pain 2007; 132: 237-51

53. Sudoh Y, Cahoon EE, Gerner P, Wang GK: Tricyclic antidepressants as long-acting local anesthetics. Pain 2003; 103: 49-55 
54. Wang SY, Calderon J, Wang GK: Block of neuronal Na+ channels by antidepressant duloxetine in a state-dependent manner. Anesthesiology 2010; 113: 655-65

55. Attal N, Cruccu G, Haanpaa M, Hansson P, Jensen TS, Nurmikko T, Sampaio C, Sindrup S, Wiffen P: EFNS guidelines on pharmacological treatment of neuropathic pain. Eur J Neurol 2006; 13: 1153-69

56. Robinson LR, Czerniecki JM, Ehde DM, Edwards WT, Judish DA, Goldberg ML, Campbell KM, Smith DG, Jensen MP: Trial of amitriptyline for relief of pain in amputees: Results of a randomized controlled study. Arch Phys Med Rehabil 2004; 85: 1-6

57. Max MB, Lynch SA, Muir J, Shoaf SE, Smoller B, Dubner R: Effects of desipramine, amitriptyline, and fluoxetine on pain in diabetic neuropathy. N Engl J Med 1992; 326: 1250-6

58. Baldessarini RJ: Drug Therapy of Depression and Anxiety Disorders, Goodman \& Gilman's the pharmacological basis of therapeutics, Eleventh edition. Edited by Shanahan F, Foltin J, Edmonson K, Brown RY. The McGraw-Hill Companies, 2006, pp 429-60

59. Holmberg G: Sedative effects of maprotiline and amitriptyline. Acta Psychiatr Scand 1988; 77: $584-6$

60. Swift CG, Haythorne JM, Clarke P, Stevenson IH: Cardiovascular, sedative and anticholinergic effects of amitriptyline and zimelidine in young and elderly volunteers. Acta Psychiatr Scand Suppl 1981; 290: 425-32

61. Perucca E, Cloyd J, Critchley D, Fuseau E: Rufinamide: Clinical pharmacokinetics and concentration-response relationships in patients with epilepsy. Epilepsia 2008; 49: 1123-41 
62. Fava M: The possible antianxiety and mood-stabilizing effects of rufinamide. Psychother Psychosom 2010; 79: 194-5

63. McWilliams LA, Goodwin RD, Cox BJ: Depression and anxiety associated with three pain conditions: Results from a nationally representative sample. Pain 2004; 111: 77-83

64. Bhattacharya A, Wickenden AD, Chaplan SR: Sodium channel blockers for the treatment of neuropathic pain. Neurotherapeutics 2009; 6: 663-78

65. Gavva NR, Treanor JJ, Garami A, Fang L, Surapaneni S, Akrami A, Alvarez F, Bak A, Darling M, Gore A, Jang GR, Kesslak JP, Ni L, Norman MH, Palluconi G, Rose MJ, Salfi M, Tan E, Romanovsky AA, Banfield C, Davar G: Pharmacological blockade of the vanilloid receptor TRPV1 elicits marked hyperthermia in humans. Pain 2008; 136: 202-10

66. Wallace MS, Rowbotham M, Bennett GJ, Jensen TS, Pladna R, Quessy S: A multicenter, double-blind, randomized, placebo-controlled crossover evaluation of a short course of 4030W92 in patients with chronic neuropathic pain. J Pain 2002; 3: 227-33

67. Nau C, Seaver M, Wang SY, Wang GK: Block of human heart hH1 sodium channels by amitriptyline. J Pharmacol Exp Ther 2000; 292: 1015-23

68. Wang GK, Russell C, Wang SY: State-dependent block of voltage-gated Na+ channels by amitriptyline via the local anesthetic receptor and its implication for neuropathic pain. Pain 2004; 110: 166-74 
69. Weiser T, Qu Y, Catterall WA, Scheuer T: Differential interaction of R-mexiletine with the local anesthetic receptor site on brain and heart sodium channel alpha-subunits. Mol Pharmacol 1999; 56: 1238-44

70. Payandeh J, Scheuer T, Zheng N, Catterall WA: The crystal structure of a voltage-gated sodium channel. Nature $2011 ; 475$ : 353-8

71. Hudson L, Bevan S, McNair K, Gentry C, Fox A, Kuhn R, Winter J: Metabotropic glutamate receptor 5 upregulation in A-fibers after spinal nerve injury: 2-methyl-6-(phenylethynyl)pyridine (MPEP) reverses the induced thermal hyperalgesia. J Neurosci 2002; 22: 2660-8

72. Gasparini F, Lingenhohl K, Stoehr N, Flor PJ, Heinrich M, Vranesic I, Biollaz M, Allgeier H, Heckendorn R, Urwyler S, Varney MA, Johnson EC, Hess SD, Rao SP, Sacaan Al, Santori EM, Velicelebi G, Kuhn R: 2-Methyl-6-(phenylethynyl)-pyridine (MPEP), a potent, selective and systemically active mGlu5 receptor antagonist. Neuropharmacology 1999; 38: 1493-503

73. Walker K, Bowes M, Panesar M, Davis A, Gentry C, Kesingland A, Gasparini F, Spooren W, Stoehr N, Pagano A, Flor PJ, Vranesic I, Lingenhoehl K, Johnson EC, Varney M, Urban L, Kuhn R: Metabotropic glutamate receptor subtype 5 (mGlu5) and nociceptive function. I. Selective blockade of mGlu5 receptors in models of acute, persistent and chronic pain. Neuropharmacology 2001; 40: 1-9

74. Zhu CZ, Wilson SG, Mikusa JP, Wismer CT, Gauvin DM, Lynch JJ, III, Wade CL, Decker MW, Honore P: Assessing the role of metabotropic glutamate receptor 5 in multiple nociceptive modalities. Eur J Pharmacol 2004; 506: 107-18 
75. Dogrul A, Ossipov MH, Lai J, Malan TP, Jr., Porreca F: Peripheral and spinal antihyperalgesic activity of SIB-1757, a metabotropic glutamate receptor (mGLUR(5)) antagonist, in experimental neuropathic pain in rats. Neurosci Lett 2000; 292: 115-8

76. Fisher K, Fundytus ME, Cahill CM, Coderre TJ: Intrathecal administration of the mGluR compound, (S)-4CPG, attenuates hyperalgesia and allodynia associated with sciatic nerve constriction injury in rats. Pain 1998; 77: 59-66

77. Fisher K, Lefebvre C, Coderre TJ: Antinociceptive effects following intrathecal pretreatment with selective metabotropic glutamate receptor compounds in a rat model of neuropathic pain. Pharmacol Biochem Behav 2002; 73: 411-8

78. Coppen A, Ghose K, Montgomery S, Rama Rao VA, Bailey J, Christiansen J, Mikkleson PL, van Praag HM, van de Poel F, Minsker EJ, Kozulja VG, Matussek N, Kungkunz G, Jorgensen A: Amitriptyline plasma-concentration and clinical effect. A World Health Organisation Collaborative Study. Lancet 1978; 1: 63-6

79. Cavaletti G, Oggioni N, Sala F, Pezzoni G, Cavalletti E, Marmiroli P, Petruccioli MG, Frattola L, Tredici G: Effect on the peripheral nervous system of systemically administered dimethylsulfoxide in the rat: A neurophysiological and pathological study. Toxicol Lett 2000; 118: $103-7$

80. Brien S, Prescott $\mathrm{P}$, Bashir N, Lewith $\mathrm{H}$, Lewith $\mathrm{G}$ : Systematic review of the nutritional supplements dimethyl sulfoxide (DMSO) and methylsulfonylmethane (MSM) in the treatment of osteoarthritis. Osteoarthritis Cartilage 2008; 16: 1277-88 


\section{Figure Legends}

Fig. 1: Rufinamide (RUF) and amitriptyline (AMI) alleviate mechanical allodynia after SNI A) RUF dose-dependently alleviates neuropathic behavior following SNI from 20 to 240 min after injection with a peak at 60 min and a loss of effect at 24h, B) AMI alleviates neuropathic behavior following SNI from 60 to 240 min after injection and losts its effect at $24 \mathrm{~h},(* \mathrm{p}<0.05, * * \mathrm{p}<0.01, * * * \mathrm{p}<0.001 \mathrm{vs}$ PreInj). BL=baseline, Preinj=pre-injection (1 week after SNI for RUF, 2 weeks for AMI), SNI=spared nerve injury, $\mathrm{DMSO}=$ dimethylsulfoxide. Values are presented as mean $\pm \mathrm{SD}$.

Fig. 2: Rufinamide (RUF) and amitriptyline (AMI) differentially affect basal sensitivity and activity of naïve animals. A) RUF at $50 \mathrm{mg} / \mathrm{kg}$ does not affect withdrawal threshold to mechanical stimulation with von Frey filaments as compared to AMI which significantly increased the threshold at the dose of $20 \mathrm{mg} / \mathrm{kg}$ (not statistically significant for $10 \mathrm{mg} / \mathrm{kg}), \mathrm{n}=8$. B) RUF at $50 \mathrm{mg} / \mathrm{kg}$ does not affect withdrawal latency to heat stimulation as compared to AMI which significantly increased the latency at the dose of 10 and $20 \mathrm{mg} / \mathrm{kg}, \mathrm{n}=8 . \mathrm{C}$ ) The total activity (in hours) of the animals was measured using the Activ-meter system over a 4 hours period following drug injection and compared to activity following saline. AMI $(10 \mathrm{mg} / \mathrm{kg})$ but not RUF $(50 \mathrm{mg} / \mathrm{kg})$ significantly reduces the activity compared to control, $\mathrm{n}=6$. Data are expressed as median (horizontal line) and box and whiskers with first and third quartiles (box), and minimum and maximum (whiskers), ns=non-significant, $* \mathrm{p}<0.05, * * \mathrm{p}<0.01$ versus control $(\mathrm{CTRL})$.

Fig. 3: Drugs inhibit voltage-gated sodium channel Nav 1.7 peak current. A) Percentage reduction of peak current after single pulse stimulation B) Example of traces with the drug concentrations used afterwards in the biophysical properties testing, respectively 
100, 10 and $100 \mu \mathrm{mol} / \mathrm{l}$ for rufinamide (RUF), amitriptyline (AMI) and mexiletine (MEX). Transients were blanked.

Fig. 4: Drugs induce a shift of inactivation properties of voltage-gated sodium channel Nav1.7. Rufinamide (RUF), amitriptyline (AMI) and mexiletine (MEX) (at respectively 100,10 and $100 \mu \mathrm{mol} / \mathrm{I}$ ) induce a hyperpolarizing shift in steady state inactivation (SSI) without changing activation (ACT) properties of the voltage-gated sodium channel Nav1.7. $v_{1 / 2}$ of activation/inactivation, slopes, $\mathrm{p}$ values and $\mathrm{n}$ values are summarized in the tables. Insert: stimulation protocols. $C T R L=$ control, values are mean $\pm S D$.

Fig. 5: Drugs induce a prolongation of recovery from inactivation of voltage-gated sodium channel Nav1.7. Rufinamide (RUF), amitriptyline (AMI) and mexiletine (MEX), at respectively 100,10 and $100 \mu \mathrm{mol} / \mathrm{l}$, prolonged in a statistically significant way the half time $\left(t_{1 / 2}\right)$ of recovery from inactivation of Nav1.7 channel. Values of interest are summarized in the table. Insert: stimulation protocol. CTRL $=$ control, values are mean $\pm S D$.

Fig. 6: Drugs induce a use-dependent block of voltage-gated sodium channel Nav1.7 Rufinamide (RUF), amitriptyline (AMI) and mexiletine (MEX), at respectively 100, 10 and $100 \mu \mathrm{mol} / \mathrm{l}$, all induced a statistically significant use-dependent block with stimulation frequencies from 2 to $50 \mathrm{~Hz}$ (except RUF at $2 \mathrm{~Hz}$ ). All frequencies are shown in tables but for clarity purposes only 10 and $25 \mathrm{~Hz}$ are shown graphically. CTRL=control, values are mean $\pm S D$

Fig. 7: Effects of rufinamide on freshly dissociated dorsal root ganglion neurons 
A) Rufinamide (RUF) at $100 \mu \mathrm{mol} / \mathrm{l}$ induced a $10 \%$ reduction in sodium peak current density ( $p=0.0084, n=7$, horizontal bars represent mean values). B) It significantly shifted the steady-state inactivation (SSI) curve to a hyperpolarizing direction $\left(\mathrm{V}_{1 / 2}\right.$ of inactivation from $-64.4 \pm 16.8$ to $-69.35 \pm 17.1 \mathrm{mV}, \mathrm{p}<0.0001, \mathrm{n}=6)$ without changing activation properties $\left(V_{1 / 2}\right.$ of activation from $-40.6 \pm 8.4$ to $\left.-43.4 \pm 5.1 m V, p=0.17, n=7\right)$. C) RUF also prolonged recovery from inactivation with half-time $\left(t_{1 / 2}\right)$ for CTRL and RUF of respectively $2.58 \pm 2.12$ and $6.24 \pm 5.04 \mathrm{~ms}, \mathrm{p}=0.0028, \mathrm{n}=6 . \mathrm{CTRL}=$ control, values are mean $\pm S D$. 


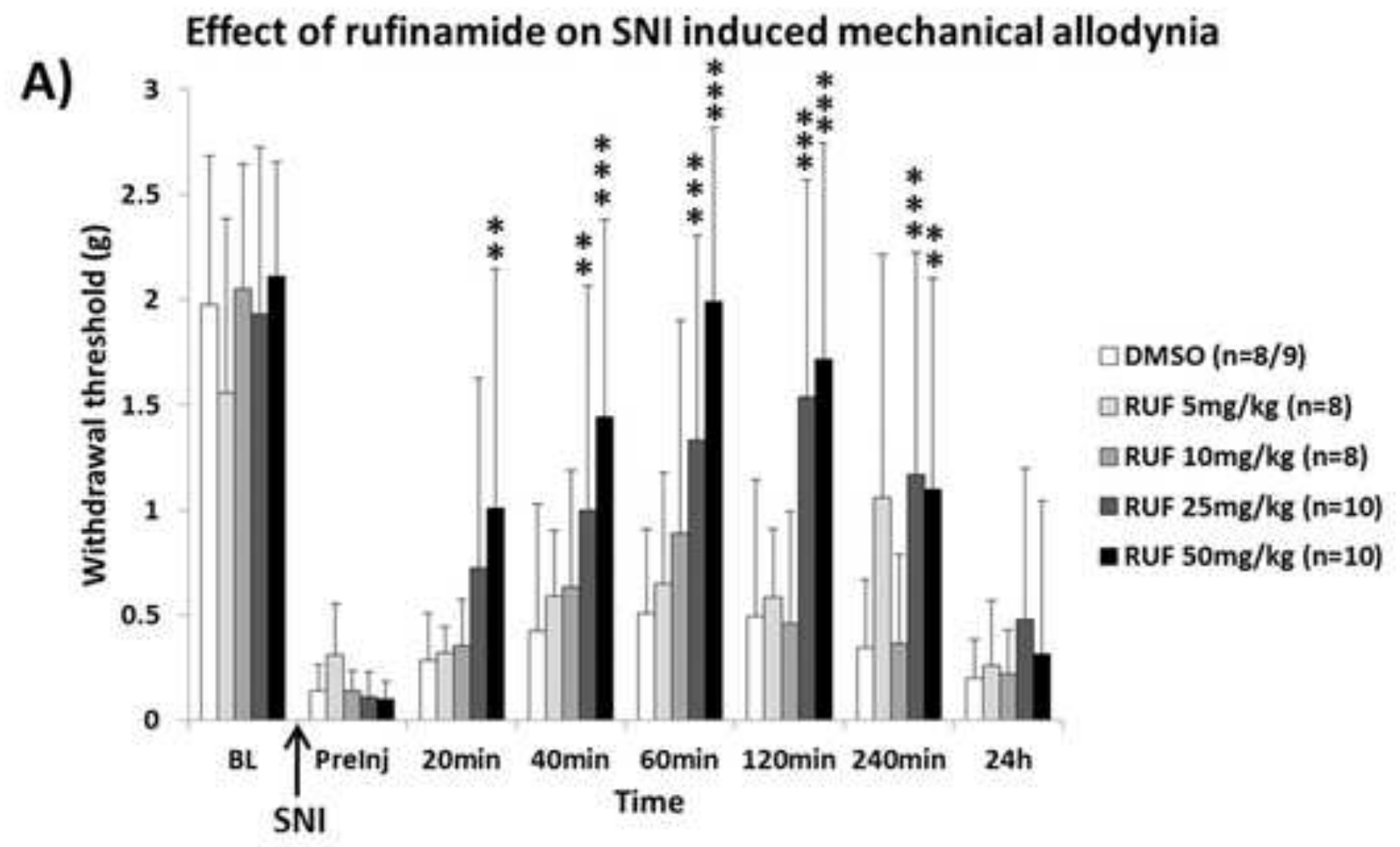

B)

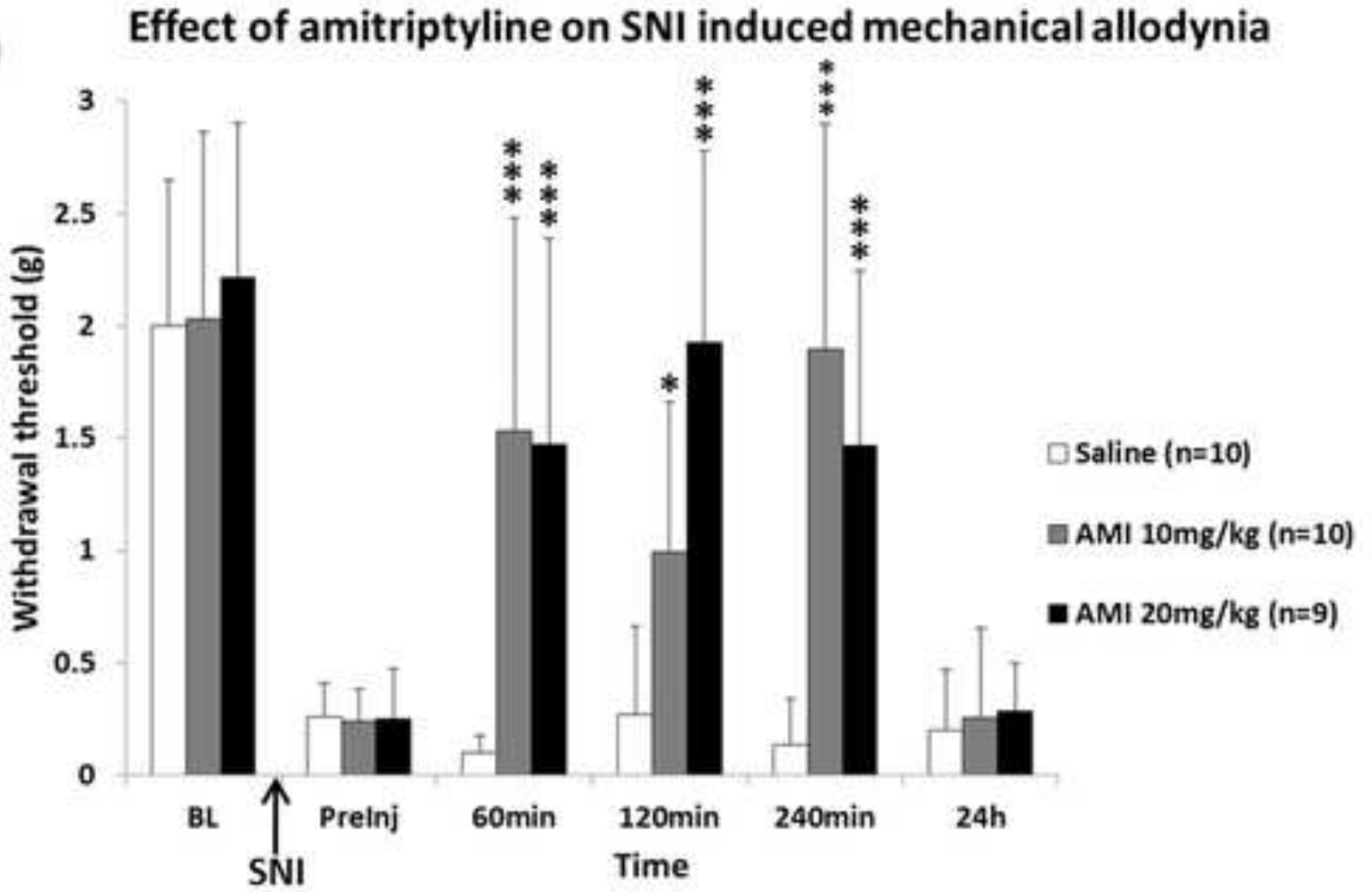


A)

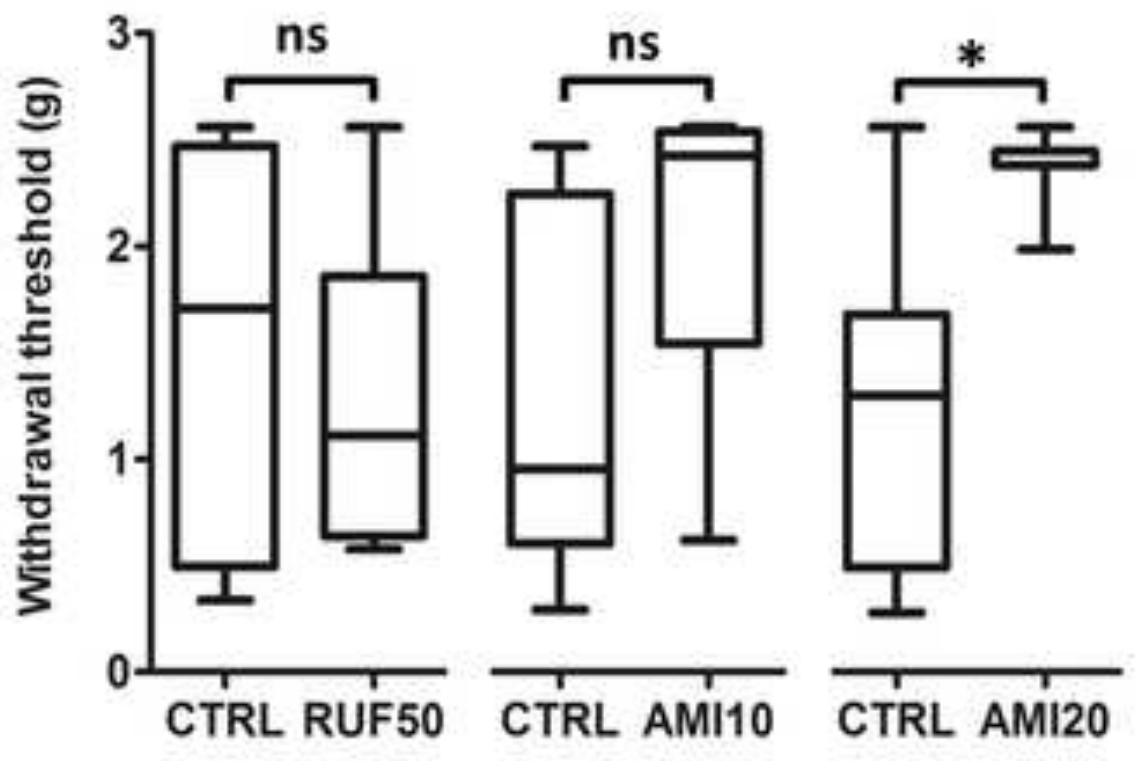

B)

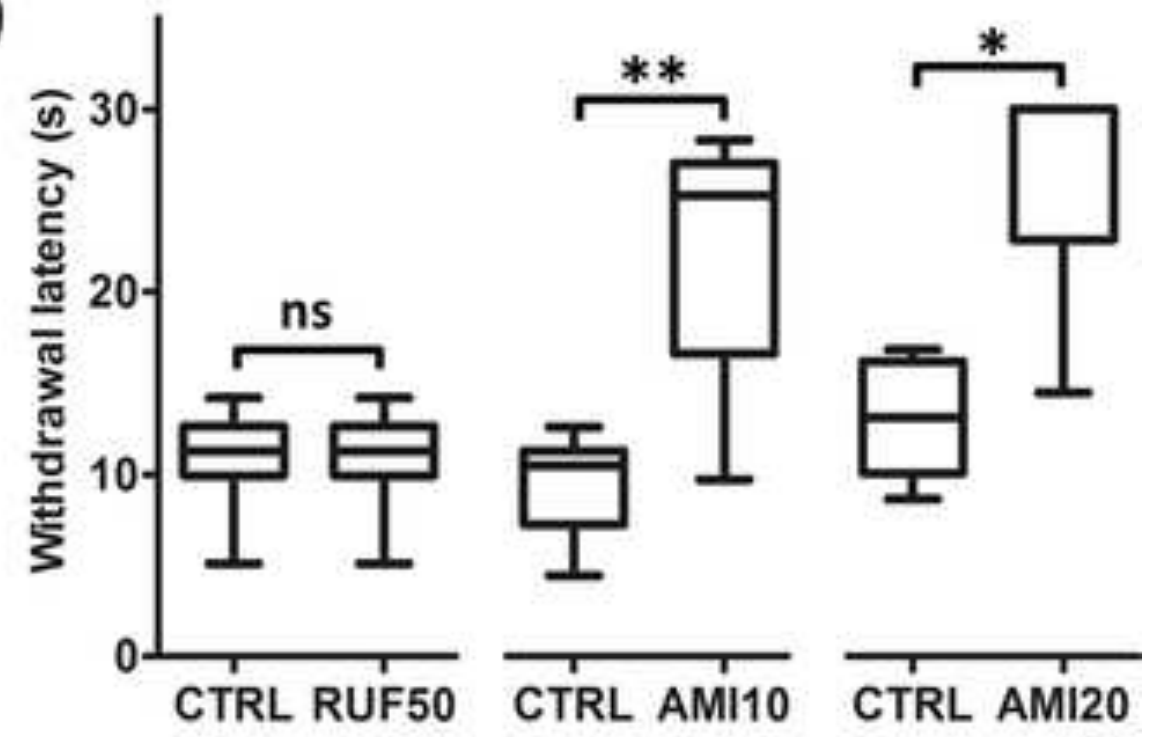

c)

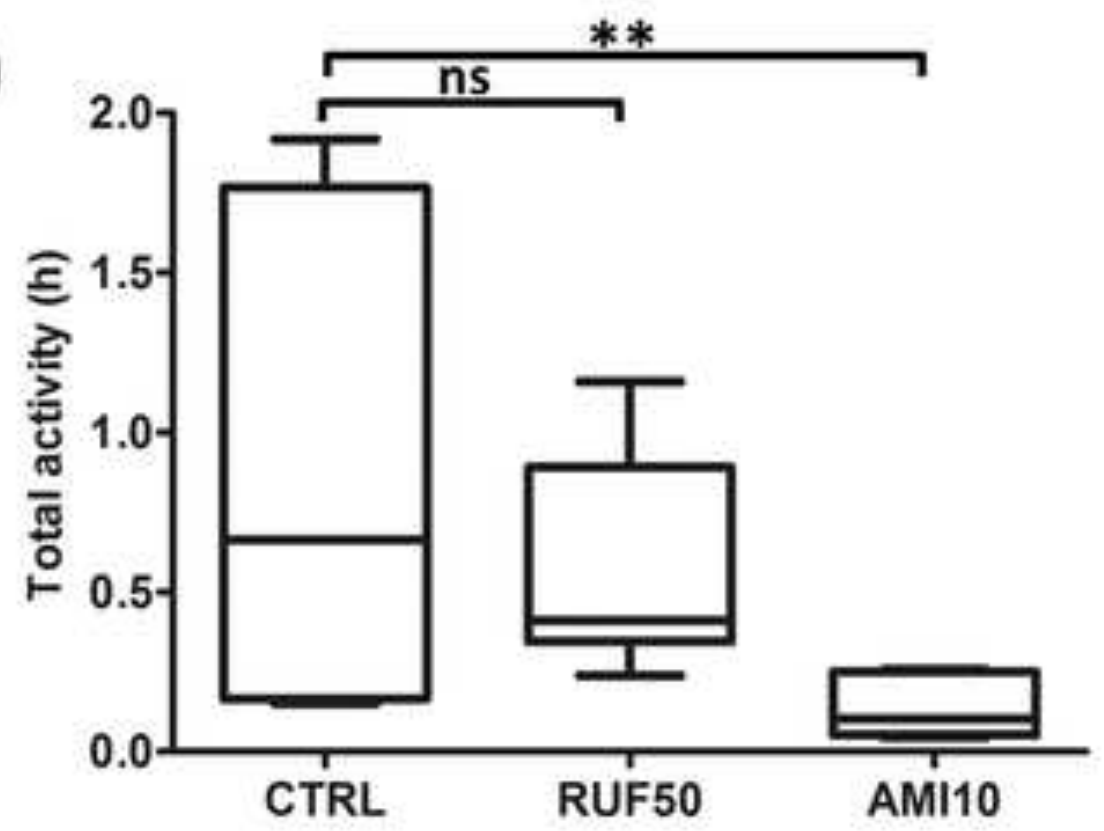


A)

\begin{tabular}{|c|c|}
\hline RUF $(\mu \mathrm{M})$ & Inhibition $(\%)$ \\
\hline 50 & 12.5 \\
\hline 100 & 21.2 \\
\hline 500 & 28.3 \\
\hline
\end{tabular}

\begin{tabular}{|c|c|}
\hline AMI $(\mu \mathrm{M})$ & Inhibition $(\%)$ \\
\hline 10 & 43.9 \\
\hline 30 & 64.7 \\
\hline 100 & 89.7 \\
\hline
\end{tabular}

\begin{tabular}{|c|c|}
\hline MEX $(\mu \mathrm{M})$ & Inhibition (\%) \\
\hline 30 & 21.7 \\
\hline 100 & 43.4 \\
\hline 160 & 67.7 \\
\hline 300 & 77.1 \\
\hline
\end{tabular}

B) RUF 100

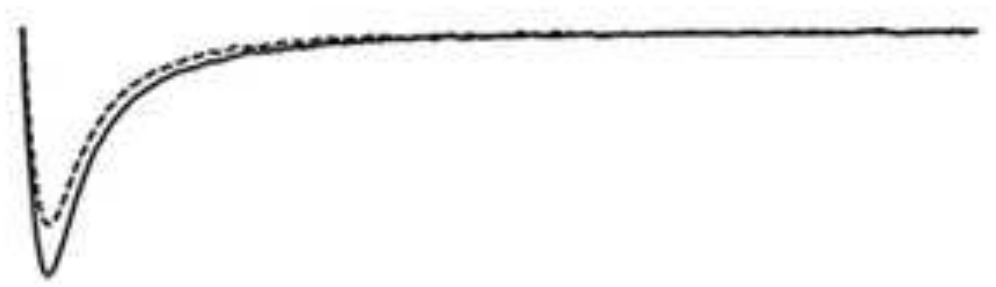

AMI 10

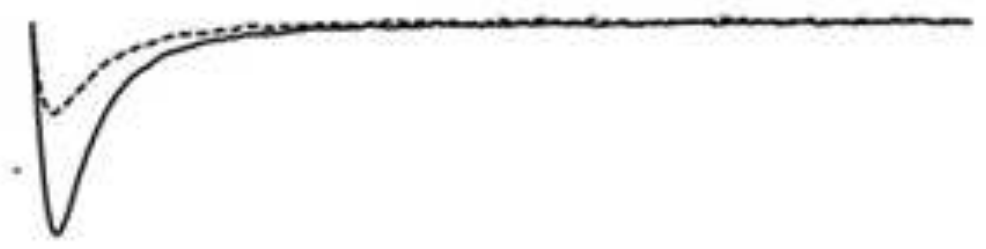

MEX 100

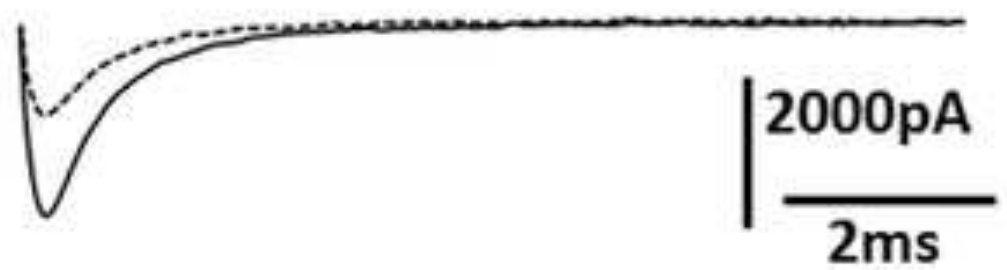




\begin{tabular}{|c|c|c|c|c|}
\hline Activation & $V_{t / 2} \pm S D(m V)$ & & Slope \pm SD & \\
\hline CTRL & $-25.8 \pm 3.3$ & $p=0.28$ & $5.5 \pm 0.8$ & $p=0.02$ \\
\hline RUF & $-26.6 \pm 2.8$ & & $6.1 \pm 1.0$ & $n=5$ \\
\hline Inactivation & $\mathrm{V}_{\mathrm{i} / 2} \pm \mathrm{SD}(\mathrm{mV})$ & & Slope + SD & \\
\hline CTRL & $-81.8 \pm 4.4$ & $P=0.0038$ & $7.3 \pm 2.4$ & $p=0.45$ \\
\hline RUF & $-87.6 \pm 4.9$ & & $7.6 \pm 2.0$ & $n=4$ \\
\hline
\end{tabular}

\begin{tabular}{|c|c|c|c|c|}
\hline Activation & $V_{1 / a} \pm$ SD $(\mathrm{mV})$ & & Slope $\pm 5 D$ & \\
\hline CTRL & $-24.8 \pm 1.2$ & $p=0.21$ & $5.2 \pm 0.5$ & $p=0.11$ \\
\hline AMI & $-27.1 \pm 2.8$ & & $6.1 \pm 1.0$ & $n=5$ \\
\hline Inactivation & $V_{L / 2} \pm$ SD $(\mathrm{mV})$ & & Slope $\pm S D$ & \\
\hline CTRL & $-78.9 \pm 2.8$ & $\mathrm{P}=0.0019$ & $7.8 \pm 1.0$ & $p=0.52$ \\
\hline AMI & $-88.4 \pm 1.1$ & & $7.7 \pm 0.9$ & $n=5$ \\
\hline
\end{tabular}
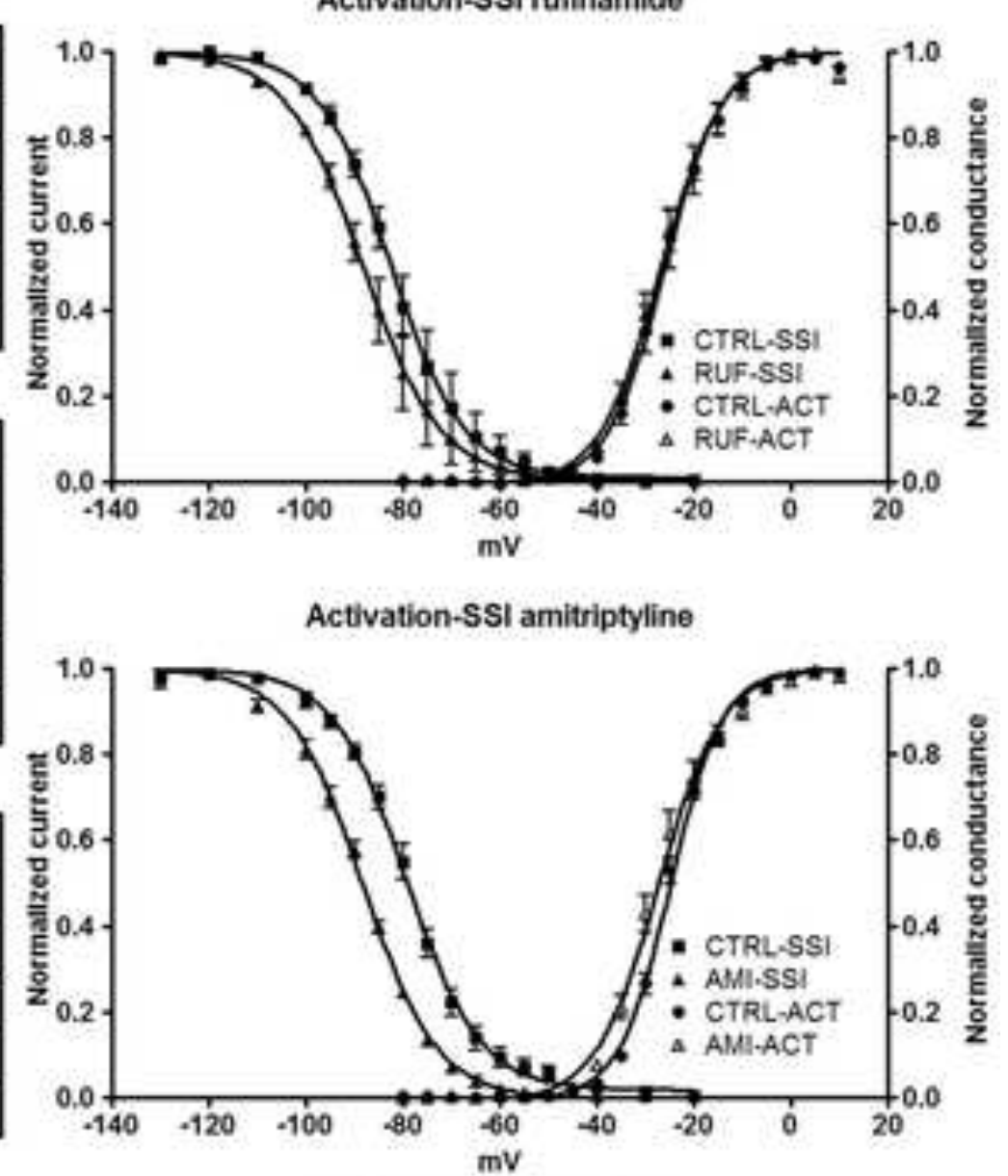

Activation protocol

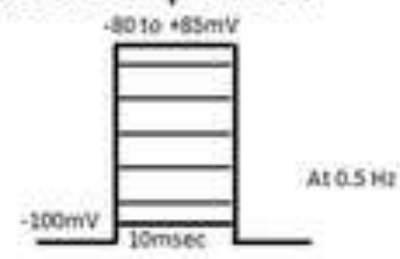

SSI protocol

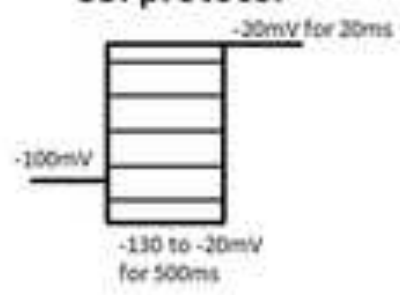

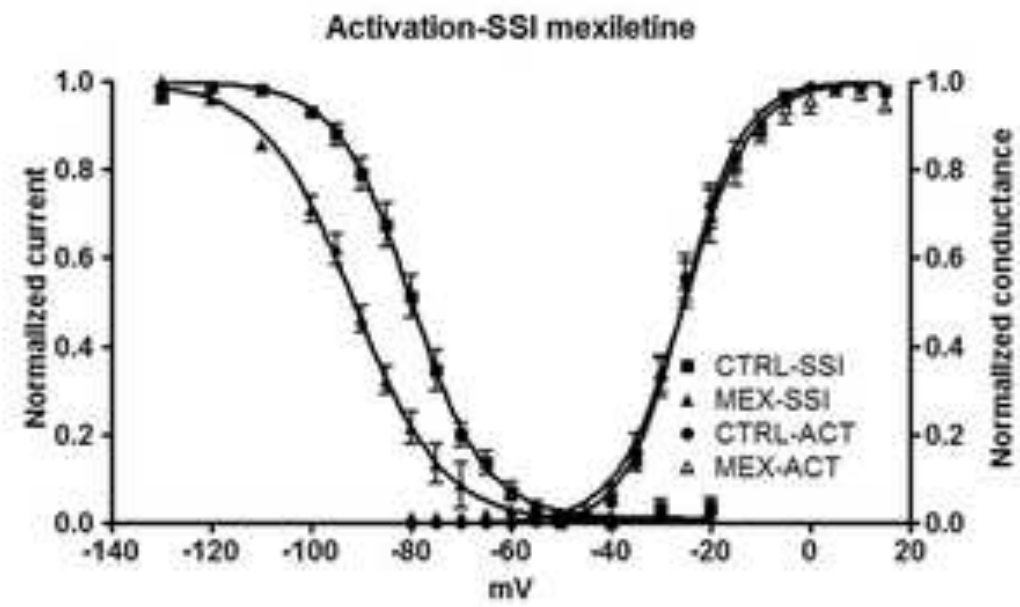


Recovery from inactivation - rufinamide

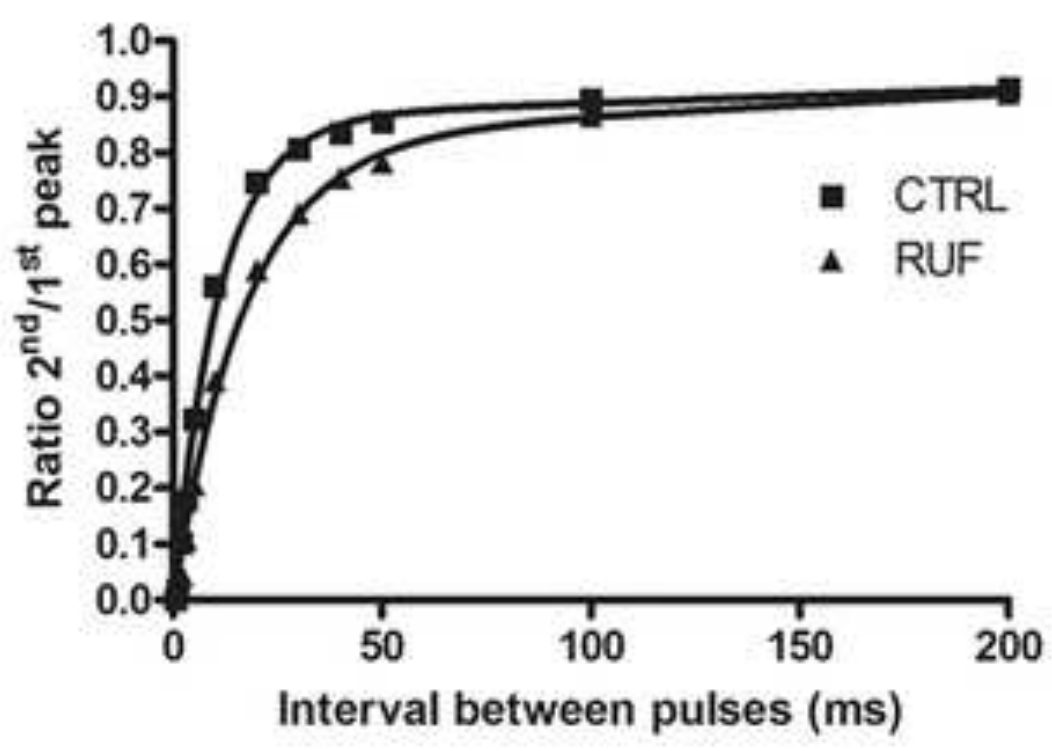

Recovery from inactivation - mexiletine

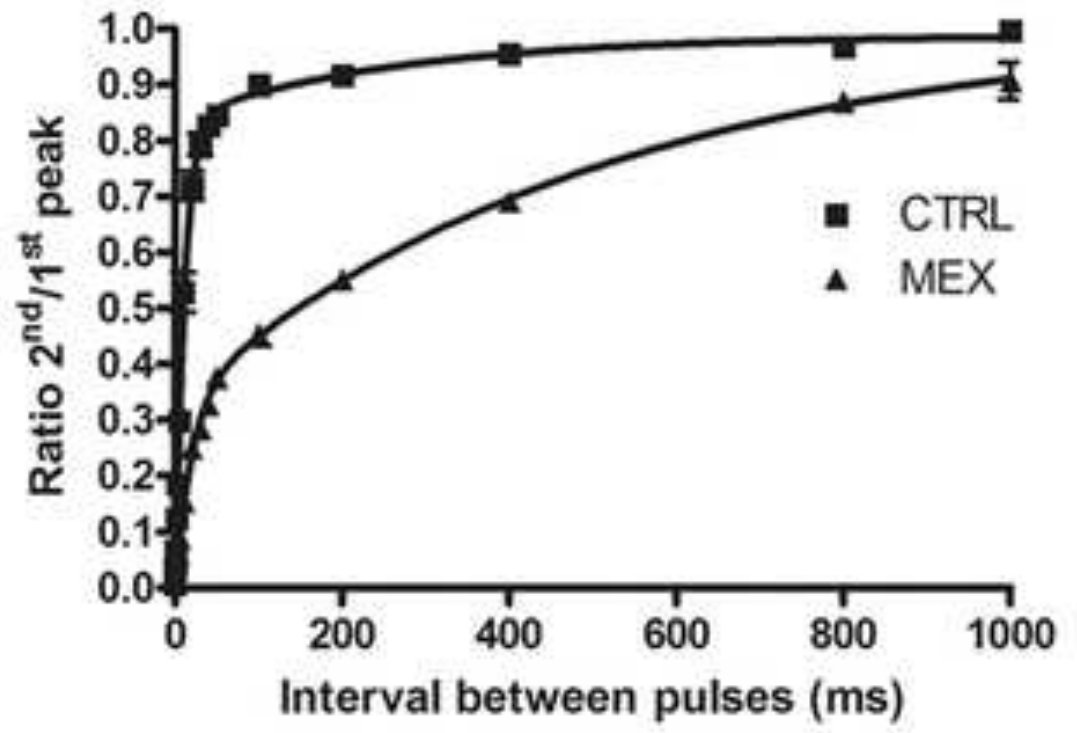

Recovery from inactivation - amitriptyline

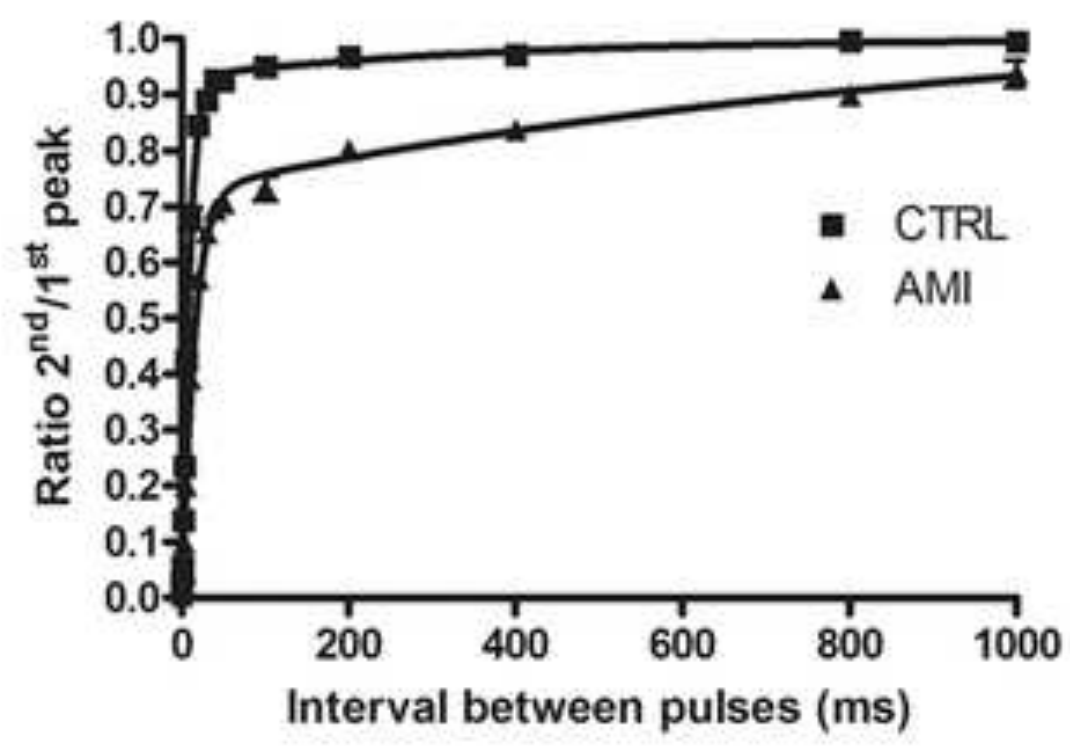

\begin{tabular}{|c|c|c|c|}
\hline & RUF & AMI & MEX \\
\hline & $t_{1 / 2}$ recovery $(\mathrm{ms})$ & $\mathrm{t}_{1 / 2}$ recovery $(\mathrm{ms})$ & $\mathrm{t}_{1 / 2}$ recovery $(\mathrm{ms})$ \\
\hline CTRL & $8.89 \pm 1.64$ & $6.48 \pm 0.64$ & $7.73 \pm 3.13$ \\
\hline Drug & $15.41 \pm 2.37$ & $16.08 \pm 1.06$ & $152.4 \pm 22.4$ \\
\hline t-test & $p<0.0001$ & $p=0.0011$ & $p=0.0002$ \\
\hline $\mathbf{n}$ & 15 & 3 & 5 \\
\hline
\end{tabular}




\begin{tabular}{|c|c|c|c|c|}
\hline \multicolumn{5}{|c|}{ Normalized current after 50 pulses } \\
\hline & CTRL & RUF & & $p$ value \\
\hline $2 \mathrm{~Hz}$ & 1.04 & 0.93 & $\mathrm{n}=5$ & 0.11 \\
\hline $5 \mathrm{~Hz}$ & 0.92 & 0.80 & $\mathrm{n}=4$ & 0.0032 \\
\hline $10 \mathrm{~Hz}$ & 0.89 & 0.71 & $\mathrm{n}=3$ & 0.033 \\
\hline $25 \mathrm{~Hz}$ & 0.69 & 0.48 & $\mathrm{n}=4$ & 0.017 \\
\hline $50 \mathrm{~Hz}$ & 0.23 & 0.10 & $\mathrm{n}=3$ & 0.033 \\
\hline
\end{tabular}

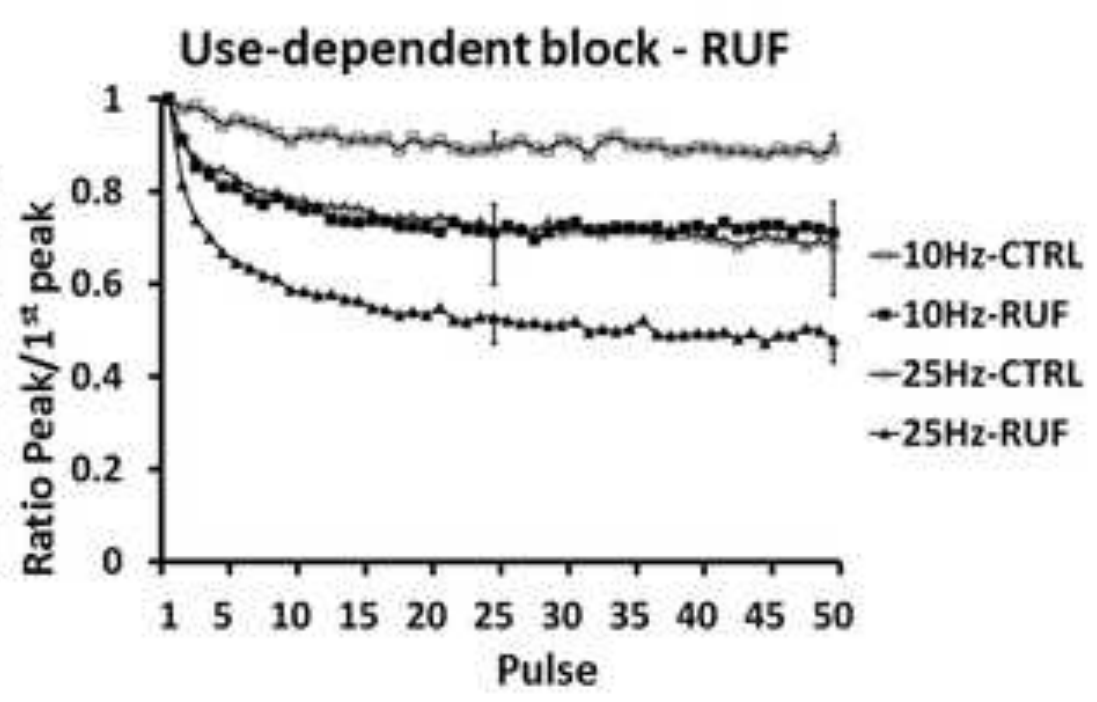

\begin{tabular}{|c|c|c|c|c|}
\hline \multicolumn{5}{|c|}{ Normalized current after 50 pulses } \\
\hline & CTRL & MEX & & $p$ value \\
\hline $2 \mathrm{~Hz}$ & 1.01 & 0.74 & $n=5$ & 0.0085 \\
\hline $5 \mathrm{~Hz}$ & 0.96 & 0.44 & $n=4$ & 0.0002 \\
\hline $10 \mathrm{~Hz}$ & 0.92 & 0.25 & $n=5$ & 0.0006 \\
\hline $25 \mathrm{~Hz}$ & 0.81 & -0.06 & $n=4$ & 0.0017 \\
\hline $50 \mathrm{~Hz}$ & 0.30 & -0.16 & $n=3$ & 0.038 \\
\hline
\end{tabular}

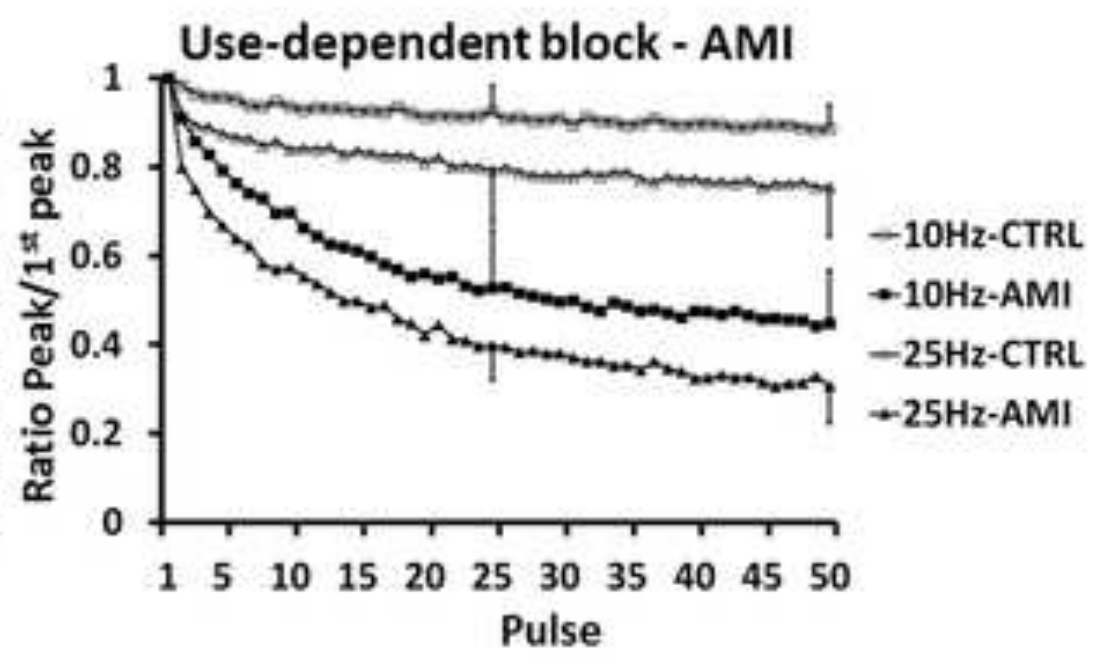

\begin{tabular}{|c|c|c|c|c|}
\hline \multicolumn{5}{|c|}{ Normalized current after 50 pulses } \\
\hline & CTRL & AMI & & P value \\
\hline $2 \mathrm{~Hz}$ & 0.99 & 0.76 & $n=5$ & 0.028 \\
\hline $5 \mathrm{~Hz}$ & 0.93 & 0.59 & $n=5$ & 0.0005 \\
\hline $10 \mathrm{~Hz}$ & 0.89 & 0.45 & $n=5$ & 0.0011 \\
\hline $25 \mathrm{~Hz}$ & 0.76 & 0.31 & $n=5$ & 0.0009 \\
\hline $50 \mathrm{~Hz}$ & 0.26 & 0.09 & $n=5$ & 0.0007 \\
\hline
\end{tabular}

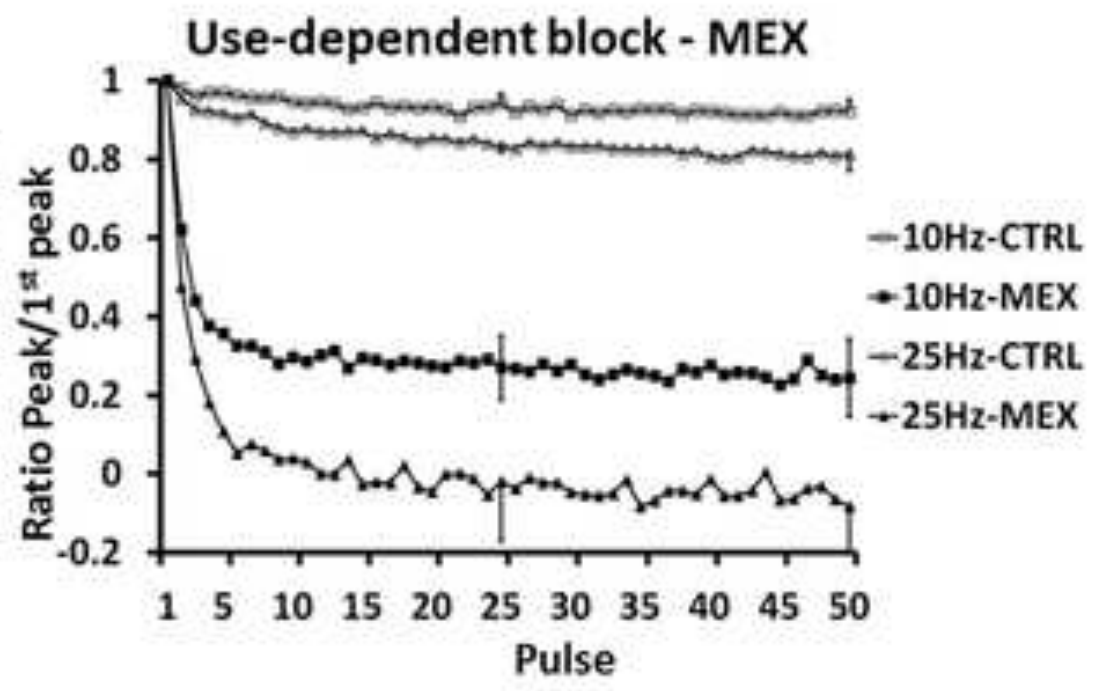


A) Peak current in dorsal root ganglion neurons

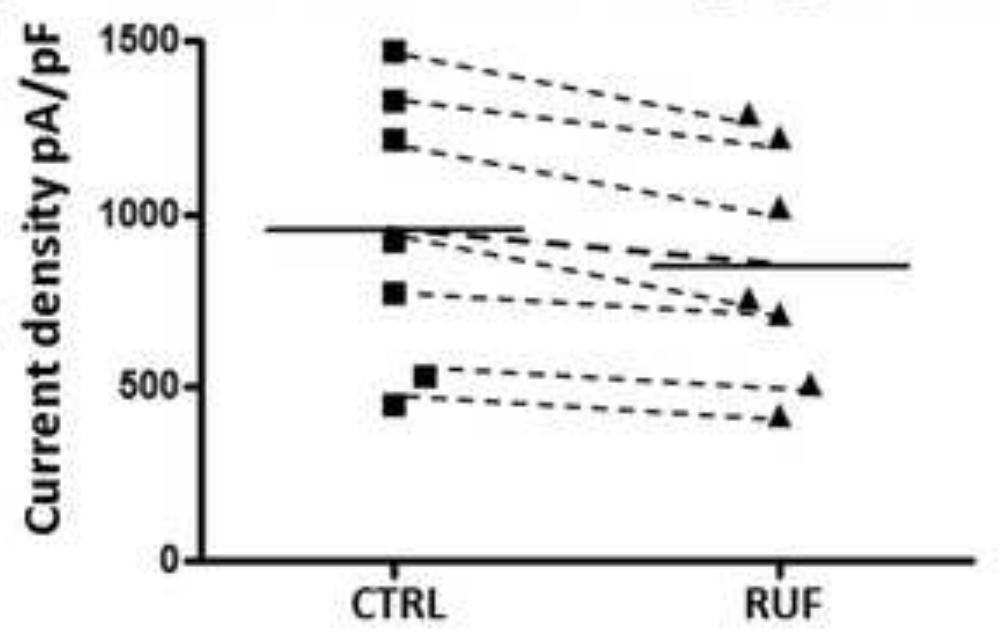

C)

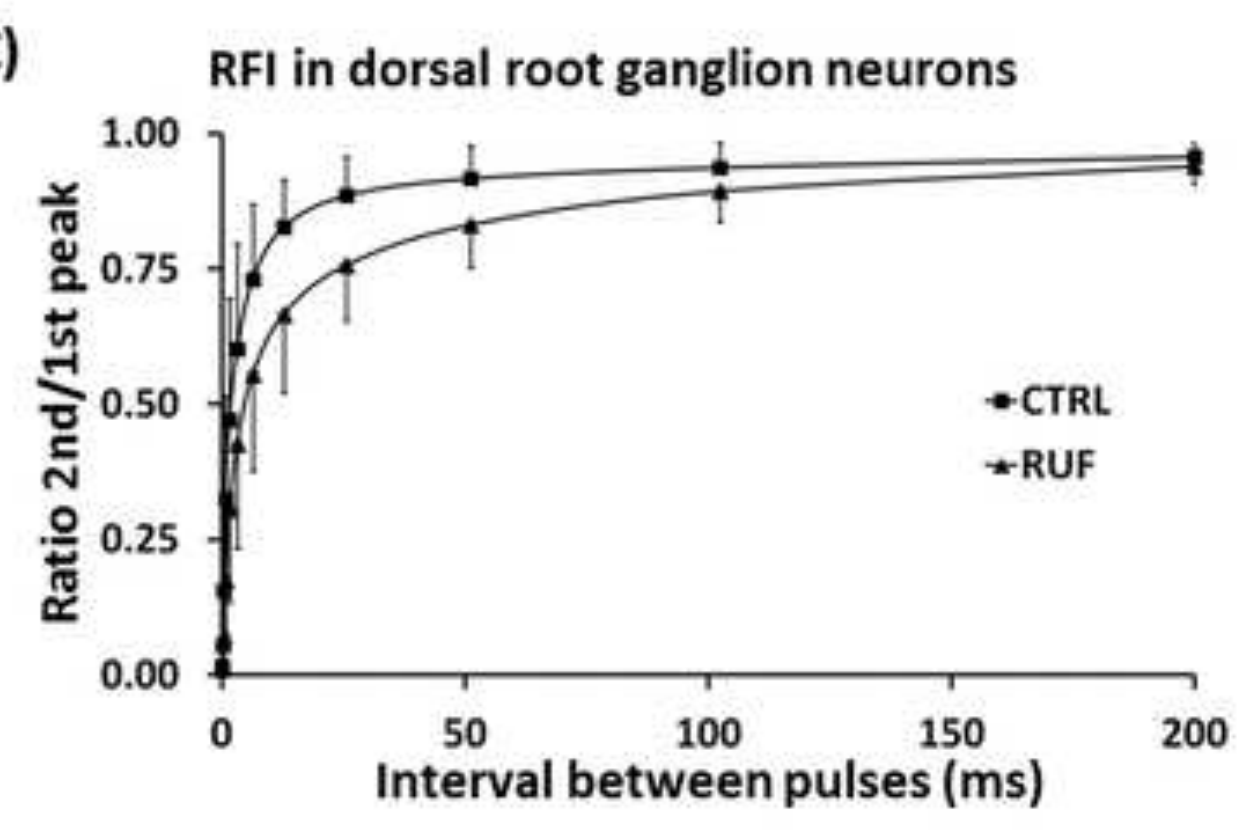

B) Activation-SSI in dorsal root ganglion neurons

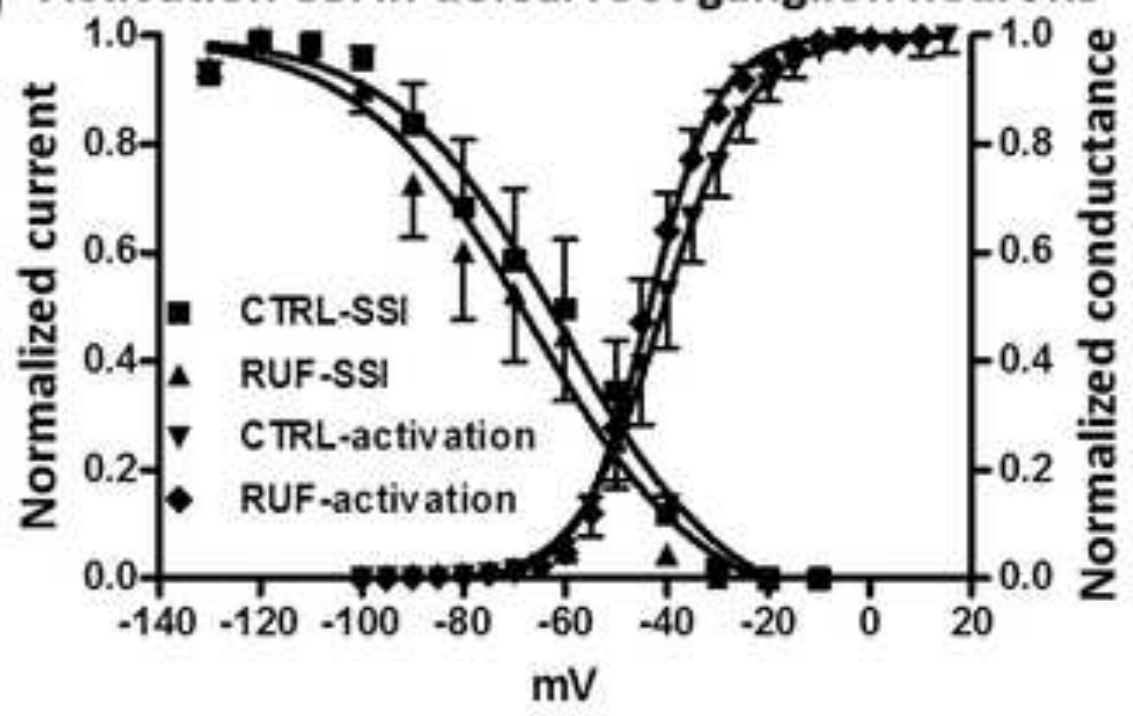

